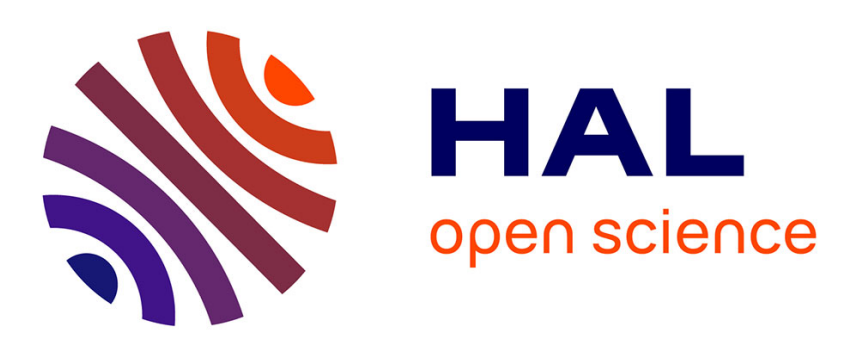

\title{
Simulation of inter- and transgranular crack propagation in polycrystalline aggregates due to stress corrosion cracking
}

\author{
Andrey Musienko, Georges Cailletaud
}

\section{- To cite this version:}

Andrey Musienko, Georges Cailletaud. Simulation of inter- and transgranular crack propagation in polycrystalline aggregates due to stress corrosion cracking. Acta Materialia, 2009, 57, pp.3840-3855. 10.1016/j.actamat.2009.04.035 . hal-00413658

\section{HAL Id: hal-00413658}

https://hal-mines-paristech.archives-ouvertes.fr/hal-00413658

Submitted on 4 Sep 2009

HAL is a multi-disciplinary open access archive for the deposit and dissemination of scientific research documents, whether they are published or not. The documents may come from teaching and research institutions in France or abroad, or from public or private research centers.
L'archive ouverte pluridisciplinaire HAL, est destinée au dépôt et à la diffusion de documents scientifiques de niveau recherche, publiés ou non, émanant des établissements d'enseignement et de recherche français ou étrangers, des laboratoires publics ou privés. 


\title{
Simulation of inter- and transgranular crack propagation in polycrystalline aggregates due to stress corrosion cracking
}

\author{
Andrey Musienko ${ }^{\mathrm{a}}$, Georges Cailletaud ${ }^{\mathrm{b}}$ \\ ${ }^{a}$ Material Strength Department, State Polytechnical University, \\ 195251, St-Petersburg, Russia \\ ${ }^{b}$ MINES ParisTech, Centre des Matériaux, CNRS UMR 7633 \\ BP 87, 91003 Evry Cedex, France
}

\begin{abstract}
The motivation of the study is the development of a coupled approach able to account for the interaction between environment and plasticity in a polycrystalline material. The paper recalls first the constitutive equations used to describe the behaviour of the grain core and of the grain boundary (GB). The procedure that is applied to generate synthetic polycrystalline aggregates with an explicit representation of the grain boundary area by $2 \mathrm{D}$ or $3 \mathrm{D}$ finite elements is then described. The approach is applied to the modeling of iodine assisted stress corrosion cracking (IASCC) in Zircaloy tubes used in nuclear power plants.
\end{abstract}

Key words: Crystal Plasticity, Stress Corrosion Cracking, Intergranular Crack Propagation, Intergranular-Transgranular Transition, Finite Elements

\section{Introduction}

Crystal plasticity is now classically used in material science to capture realistic strain fields at a local scale. The present work would like to enlarge the approach, in order to be able to describe fracture mechanisms.

Email addresses: musienko@mat.ensmp.fr (Andrey Musienko), Georges.Cailletaud@ensmp.fr (Georges Cailletaud) 
The motivation of the study is the prediction of iodine-assisted stress corrosion cracking of Zircaloy tubes used in nuclear power plants. Laboratory tests show that crack occurs first at grain boundaries, which are made brittle due to the formation of zirconium hydrides, and that the propagation mode switches from intergranular (IG) to transgranular (TG) after a few grains.

A lot of papers dealing with the simulation of the mechanical effect of grain boundaries can be found in the literature. A natural way to model the effects at grain boundaries is to formulate a cohesive zone model. The pioneering work was made by [1] and [2] who introduced this new concept. It was at first considered as a simple solution to take into account the plastic zone near the crack tip, in order to modify the plastic solutions due to Griffith or Muskhelishvili. The idea has then been applied to build a finite element. This element has a variable stiffness, in tension and shear, but no physical width. It is able to connect the relative displacements of the two phases and the stresses at the interface. The first version was proposed in [3]. Several authors have then included other phenomena like damage and Bauschinger effect. Normal and tangent components are introduced [4, 5, 6, 7]. As pointed out in a recent review [8], this class of model can be applied to any type of interface, and is intermediate between continuum damage mechanics and fracture mechanics. So, the behavior of the boundary layer is described by means of a normal and a tangential displacement, and the corresponding forces. Damage evolution produces a transition between the initial state for which the GB is elasto(visco)plastic (damage equal zero) and the broken state (damage equal to 1). Other authors, as [9][6] [10] [11] use the asymptotic method. They study a plane strain state of two infinite elastic bodies, separated by a thin elasto-visco-plastic layer (of depth $\delta$ ).

The choice made in the present study, consists in accepting the continuous formalism of damage mechanics [12], written in terms of stress and strain, keeping in mind that the grain boundary is a highly anisotropic area. It will be modeled in a finite element (FE) mesh by classical elements, with a specific local behavior.

Following the ideas of the early papers dealing with homogenization [13], recent papers on inter-granular crack propagation use simplified grain shapes, e.g. cubes [14], hexagons for 2D case in [15], or truncated octahedrons for $3 \mathrm{D}$ case in [16]. Such a simplification allows the authors to reach a realistic grain number in their simulations $(30 \times 30 \times 30$ grains in [16]). On the other hand, this type of mesh cannot predict local stress-strain fields inside the grains. That is why real-like aggregates, generated by Voronoï tessellation, 
are used in this paper. Such a grain geometry has been extensively used in computational material science (see for instance [17][18]). Computations using hexagonal 2D structures were also performed for comparison purpose. Recently, authors [19] used Voronoï type meshes, but restrict themselves to very crude material models, without any description of crystal plasticity.

The grain boundary behavior is known to be strongly dependent on the misorientation angle [20]. Namely, low angle boundaries seem to be more resistant to intergranular fracture [21], high-angle boundaries are reported to stop the cleavage (transgranular) cracks. Analytical models for mixed intertransgranular fracture with simplified grain shapes (hexagons for 2D and truncated octahedra-tetrakaidecahedra for 3D) were proposed in [22, 23]. Fracture toughness is calculated by the authors for both straight (inter-trans granular) and zig-zag (IG) crack path. The influence of grain shape and the fraction of resistant low-angle grain boundaries is captured by this simple approach. An attempt can be found in the literature to account for this effect, by introducing different fracture criteria for low-angle and high-angle boundaries [16]. The present paper uses the same approach for all the grain boundaries: GB opening is related to the normal stress, GB sliding is produced by the shear stress component in the GB plane. Coupled computations are performed by introducing a weak coupling between mechanics and environment, that is represented by diffusion at the GB.

The paper is organized as follows. In section 2, we will review the preexisting experimental observations, concerning stress-corrosion cracking and the effects related to grain boundaries, independently of corrosion. As a conclusion, we will extract basic mechanisms, necessary for our modelling procedure. After this preliminary part, in section 3, we will present the technical details of our approach, including specific finite element meshes, material models, the method used for the description of corrosion, and the boundary conditions. The strategy chosen to determine the material parameters will be commented. Finally, results will be presented in section 4, and the closing discussion in section 5 .

\section{Experimental background}

The stress corrosion cracking phenomenon (SCC) promotes the formation of brittle cracks in normally ductile metals through the joint action of a tensile stress and a corrosive environment. This effect appears for a number of materials, such as stainless steels [24], copper [25], and Zircaloy in iodine 
environment - the subject of present study. The purpose of this section is neither to provide a comprehensive review of the literature on this large subject nor to propose a unique explanation of its mechanism. The adopted approach starts from the particular case of Zircaloy in iodine environment, and considers the related basic mechanisms, in order to develop a generic framework. The material parameters are adjusted to fit the available material data. The application of the approach to other materials will then be discussed.

\subsection{Stress corrosion cracking of Zircaloy in iodine environment}

The purpose of this section is to provide a physical basis for the development of the model. A short list of experimental facts observed in Zircaloy SCC is extracted from the literature. They are summarized below.

Interaction with fission products. Iodine and Cesium were found in cracked claddings. Authors generally agree to point out their critical role in the fracture process. A review of this subject can be found for instance in [26] [27]. The study will account for the presence of these products in damaged grain boundaries. This will generate a coupled problem between the concentration of the species and the mechanical variables.

Rupture modes. A typical rupture surface of Zircaloy in iodine environment consists of two zones, showing intergranular and transgranular failure. This basic result was obtained experimentally by [28]. It is illustrated in Fig.1a [29], where initial crack development is intergranular, and the remaining life is spent in transgranular mode. A typical inter-transgranular transition is shown in Fig.1b [30]. In fact, depending on the loading conditions, either intergranular cracking happens first, followed by transgranular crack propagation, or sometimes transgranular followed by intergranular [31], and even purely transgranular [32] or purely intergranular [33].

In [28],[29],[30], the tests are performed under prescribed strain rate, in an aggressive environment. As a consequence, the first stage of cracking happens for relatively small stress levels, without plastic strain, and it is intergranular. As the crack goes on, the effective cross section of the specimen is smaller, and the stress level goes up. After some critical stress (or plastic strain) value, the fracture type changes into transgranular mode.

On the other hand, in [31], the experiment was made on DCB (double cantilever beam) specimens, which were first loaded (by inserting a wedge 
into the machined notch) and then put into an aggressive atmosphere. In that case, the maximum loading takes place at the beginning of the test. This strategy generates transgranular fracture as a first stage, then intergranular failure, followed by a crack arrest.

Fracture can be purely transgranular under high sustained load [32], or in the case of single crystal [34]. Fracture can also be purely intergranular, if the specimen is first kept in iodine environment: a one-millimeter rod was kept for 40 hours, and then loaded in [33].

Inter-transgranular transition. It was shown that transgranular cracks initiate near grain boundaries, when intergranular propagation becomes hardly possible, due to the local geometrical arrangement. In Fig.1c, the upper grain (1), which is favourably oriented for prismatic slip to occur, shows large plastic deformation, while grain (2) which is not favourably oriented does not. The initiation sites of the transgranular cracks generally coincide with the intersections of coarse slip bands and the grain boundary [30]. They extend along basal planes $\{0001\}$ into grains which are oriented less favourably for prismatic slip. More detailed studies [28], or [29] (Fig.1d) show that transgranular crack propagation is rather the result of a competition between quasi-cleavage (brittle fracture) and fluting in the prismatic planes (ductile fracture). In the present study, only cleavage in basal planes will be considered.

\subsection{General grain boundary effects}

In any kind of loadings, the grain boundary area is a region where series of mechanical constraints due to non compatible slip occur. This results in damage development. There are two types of damage mechanisms, grain boundary sliding and opening of grain boundary.

Grain boundary sliding. In addition to intragranular slip, following specific slip directions and slip planes, slip can also happen at grain interfaces (grain boundary sliding). This effect has been observed experimentally (see for instance [35]). Figure 1e shows a particle of $\mathrm{B}_{2} \mathrm{O}_{3}$ at the grain boundary of a deformed copper bi-crystal. Starting from a circular shape before deformation, the particle is now cut into two half-spheres. In this case, slip does not produce any volume change, the grain boundary can then be seen as an additional "slip" plane, defined by the geometry instead of being defined by crystallography. 
Grain boundary opening. Besides slip, aggregate deformation can be also caused by crack opening at grain boundaries inside the polycrystal. This is illustrated in Fig.1f, where open grain boundaries are perpendicular to the tension direction (horizontal on the image). This is intergranular cracking of Zircaloy, caused by the presence of an aggressive iodine environment. This damage type will be associated some volume change. This is an example of unilateral damage, which evolution is related to the positive normal stress on the grain boundary plane.

\section{Numerical tools}

\subsection{Finite element mesh and boundary conditions}

A two step procedure is applied to generate the synthetic aggregates used in this work. The space is partitioned by means of a Voronoï tessellation, using a code developed in [36]. Let $D \subset R^{2}\left(R^{3}\right)$ to be a real domain, and $E=\left\{A_{i}\right\}$ - a number $N$ of random points, so that $A_{i} \in D$. Let also $d\left(P_{1}, P_{2}\right)$ to be an euclidean distance between points $P_{1}$ and $P_{2}$. The influence zones of the center $A_{i}$ are defined according to the following rules:

$$
z i\left(A_{i}\right)=\left\{P \in D \mid d\left(P, A_{i}\right)<d\left(P, A_{j}\right) \forall j \neq i\right\}
$$

The centers of the polyhedra are spatially distributed, following a predefined random law. In this work, the method using a repulsion distance is used. This allows us to control a minimum size of the grains and to obtain a regular grain size distribution.

The second step consists in inserting grain boundaries. Grain interfaces become now "open", and additional finite elements are added to represent grain boundaries (GB). For the $2 \mathrm{D}$ case, GB are represented by quadrilateral elements. Linear or quadratic elements are accepted, with one or two layers per GB width. For the triple points, either triangles are introduced, or the shape of the quadrilaterals is modified. For the case of $3 \mathrm{D}$ geometries, grain boundaries, that are now volumetric elements, create a quite complex structure. Elements in the current GB are bricks, but prisms and thetrahedra are also needed to connect the joints at the triple lines and multiple points. A careful examination of all the geometrical situations has been made, and a specific code, written in $\mathrm{C}++$, is available for any type of mesh generation. Typical meshes are shown in Fig.2, that illustrates the results of several realizations made with 100 germs. Figure 3 provides a detailed view to the 
shape of the grain boundary elements at triple points (Fig.3a), and a zoom to characterize the respective sizes of the grain boundaries and of the grain core (Fig.3b). For the sake of comparison, Fig.4 shows the hexagonal periodic structure. The result of the $3 \mathrm{D}$ mesh generation process is given in Fig.5. For all the 2D meshes, the thickness of the grain boundaries is $0.1 \mu \mathrm{m}$; it is divided into two flat elements. The average size of the grains is $10 \mu \mathrm{m}$. The same values are used for the 3D meshes.

Boundary conditions are chosen in such a way that:

- Diffusional boundary conditions represent a permanent presence of iodine on one side of the aggregate $(x=0)$.

- Mechanical boundary conditions represent a simple tension at a strain rate of $2 \times 10^{-4} \mathrm{~s}^{-1}$, as in [37]. Displacements were imposed as shown in Fig.6.

\subsection{Constitutive equations}

Basic single crystal model. A single crystal visco-plastic model proposed in [38] and [39], is used for the grain core. After its initial implementation [39] in the Finite Element code ZSeT/ZéBuLoN, it has been used in a series of finite element analyses of various aggregates [17][18][37][40]. The equations used in small strain are first recalled below. In the following, $\gamma^{s}$ is the viscoplastic shear on system $s, v^{s}$ its accumulated value (the derivative of the second is the absolute value of the first one), and $\eta^{s}$ is the sign of $\left(\tau^{s}-x^{s}\right)$. The slip rate is determined in a viscoplastic framework, by means of the resolved shear stress $\tau^{s}$, the isotropic hardening variable $r^{s}$, and the kinematic hardening by the variable $x^{s}$ (eq.2). The orientation tensor $\mathbf{m}_{\sim}^{s}$, that is computed for each system $s$ as the symmetric part of the tensorial product of the normal to the slip plane $\underline{\mathbf{n}}^{s}$ and the slip direction $\underline{\mathbf{l}}^{s}$ (eq.3), is used to evaluate the resolved shear stress $\tau^{s}$ and the viscoplastic strain rate tensor, $\dot{\sim}^{p}$ (eq.4). The hardening variables $r^{s}$ and $x^{s}$ respectively depend on the state variables $\rho^{s}$ and $\alpha^{s}$ (eq.5), the evolution of which is non linear (eq.6). Two parameters, $Q$ and $b$ (and the components $h_{r s}$ of the interaction matrix) represent isotropic hardening. Two parameters ( $c$ and $d$ ) characterize kinematic hardening. In the material of the study, the viscous effect is low, and the calibration of the material parameters is made accordingly. The initial conditions are $\gamma^{s}(t=0)=v^{s}(t=0)=\rho^{s}(t=0)=\alpha^{s}(t=0)=0$. The initial conditions are also taken into account through the value of the initial resolved shear stress, $\tau_{0}$.

$$
\dot{\gamma^{s}}=\left\lfloor\frac{\left|\tau^{s}-x^{s}\right|-r^{s}-\tau_{0}}{K}\right\rfloor^{n} \operatorname{sign}\left(\tau^{s}-x^{s}\right)=\dot{v}^{s} \eta^{s}
$$




$$
\begin{gathered}
\underline{\sim}^{s}=\left(\underline{\mathbf{n}}^{s} \otimes \underline{\mathbf{l}}^{s}+\underline{\mathbf{l}}^{s} \otimes \underline{\mathbf{n}}^{s}\right) / 2 \\
\tau^{s}={\underset{\sim}{\mathbf{m}}}^{s}: \underset{\sim}{\sigma} ; \quad{\underset{\sim}{\dot{\varepsilon}}}^{p}=\sum_{s} \dot{\gamma}^{s} \underline{\sim}^{s} \\
r^{s}=b Q \sum_{r} h_{s r} \rho^{r} \quad ; \quad x^{s}=c \alpha^{s} \\
\dot{\rho}^{s}=\left(1-b \rho^{s}\right) \dot{v}^{s} ; \quad \dot{\alpha}^{s}=\left(\eta^{s}-d \alpha^{s}\right) \dot{v}^{s}
\end{gathered}
$$

Model extension to represent transgranular fracture mode. Cleavage is a failure mode that appears on specific planes where the cohesive force is a minimum, creating flat fracture surfaces which follow crystallographic planes, when external loading exceeds interatomic forces. For the case of Zircaloy in iodine environment, the plane of transgranular fracture is the basal plane.

Cleavage can be represented inside the crystal plasticity formalism, using a tensorial product of the vector normal to the cleavage plane, $\underline{\mathbf{n}}$, to model crack opening. Assuming that the critical variable for cleavage is the normal stress $\sigma_{c l}=\underline{\mathbf{n}} \cdot \underset{\sim}{\sigma} \cdot \underline{\mathbf{n}}$ and $R_{c l}$ the cleavage threshold, cleavage failure will take place when the stress reaches $R_{c l}$. In the present work, instead of a pure time independent formalism, a time dependence is introduced, in order to regularize the solution, but the exponent $n$ is taken large enough, so that the rate sensitivity remains negligible. The opening is taken into account by a pseudo-strain, according to:

$$
\begin{gathered}
\stackrel{\sim}{\dot{\varepsilon}}^{c l}=\dot{\delta}^{c l} \underline{\mathbf{n}} \otimes \underline{\mathbf{n}} \\
\dot{\delta}^{c l}=\left\langle\frac{\sigma_{c l}-R_{c l}-Q\left(1-\exp \left(-b \delta^{c l}\right)\right)}{K}\right\rangle^{n}
\end{gathered}
$$

A negative value of the parameter $Q$ is chosen in order to produce softening and promote a fast propagation of the cleavage damage.

DOS model. An other extension of the classical crystal plasticity model is introduced in the grain boundary elements. "DOS" stands for Damage, Opening and Sliding of grain boundaries (GB). GB is supposed to be a regular surface. The constitutive equations are expressed in a local framework: the axis $x_{1}$ is normal to the plane, axes $x_{2}$ and $x_{3}$ are in the plane of the GB. The constitutive equations should take into account the anisotropy, namely, the GB material should resist to a normal stress, applied in $x_{1}$ direction, but neither in $x_{2}$ nor in $x_{3}$. In the initial implementation, we considered that the 
material must be very stiff in the normal direction, so that the grains remain pasted in absence of damage. Following the same idea, the moduli must be low in the transverse direction, so that the boundaries do not carry any load and do not perturb the grain equilibrium.

As well, GB should accept in-plane shear (12 and 13), but not 23 shear. These ideas are consistent with the "springs" proposed by [41]. Such an anisotropy leads to the special elastic tensor form:

$$
\underset{\sim}{\Lambda}=\operatorname{diag}(\mathrm{E}, \eta, \eta, \mu, \eta, \mu)
$$

where the terms $\eta$ remain small. Their effect will be neglected in the following, to let GB just follow the grain behavior for 22, 33 and 23 stress components. Having this anisotropy in mind, the scheme of damage mechanics must be adapted. Introducing only one variable $D$ figuring scalar damage, the classical approach [12] proposes a modification of the elasticity related part of the free energy, so that:

$$
\rho \psi_{e}=\frac{1}{2}(1-D) \underset{\sim}{\varepsilon^{e}}: \underset{\sim}{\Lambda}:{\underset{\sim}{\varepsilon}}^{e}
$$

The variable $Y$ energetically conjugated with $D$ is obtained by taking the opposite of the partial derivative of $\rho \psi_{e}$ with respect to $D$. Using the previously defined elastic tensor, and preserving only the three predominant terms, it comes:

$$
\begin{aligned}
Y=-\frac{\partial \rho \psi_{e}}{\partial D} & =\frac{1}{2} \underset{\sim}{\varepsilon^{e}}: \underset{\sim}{\Lambda}: \underset{\sim}{\varepsilon^{e}}=\frac{1}{2(1-D)^{2}} \underset{\sim}{\sigma}:{\underset{\sim}{\Lambda}}^{-1}: \underset{\sim}{\sigma} \\
& =\frac{1}{2(1-D)^{2}}\left(\frac{\sigma_{11}^{2}}{E}+\frac{\sigma_{12}^{2}+\sigma_{13}^{2}}{\mu}\right)=\frac{1}{2(1-D)^{2}}\left(\frac{\sigma_{n}^{2}}{E}+\frac{\tau^{2}}{\mu}\right)
\end{aligned}
$$

As expected, GB opening $\delta$ and GB sliding $\gamma$ will respectively correspond to $\sigma_{n}$ and $\tau$, and $D$ will correspond to $Y$. In the following, a new variable $\sigma_{d}$ will be considered instead of $Y$ :

$$
\sigma_{d}=\sqrt{\sigma_{n}^{2}+\beta \tau^{2}}=(1-D) \sqrt{2 E Y}
$$

In this variable, which is derived from $Y$, the coefficient $\beta$ characterizes the ratio $E / \mu$. For a zero value of $\beta$, damage will be driven by the normal stress only. 
The evolution equations for $D, \delta$ and $\gamma$ are defined in the framework of a viscoplastic multipotential approach, since all the phenomena are ratedependent. To get correct constitutive equations, respecting the second principle of thermodynamics, it is enough to chose convex potentials for all three variables. These potentials should depend on the associated stresses. Nortonlike viscous potentials with a threshold are chosen. The potential driving the normal flow depends on the positive part of $\sigma_{n}$, meanwhile shear depends on the absolute value of $\tau$ :

$$
\begin{array}{ll}
F_{n}=\frac{K_{n}}{n_{n}+1}\left\langle\frac{f_{n}}{K_{n}}\right\rangle^{n_{n}+1} & \text { with } f_{n}=\frac{<\sigma_{n}>}{1-D}-R_{n} \\
F_{t}=\frac{K_{t}}{n_{t}+1}\left\langle\frac{f_{t}}{K_{t}}\right\rangle^{n_{t}+1} & \text { with } f_{t}=\frac{|\tau|}{1-D}-R_{t} \\
F_{d}=\frac{2 Y}{r+2}\left[\frac{\sqrt{2 E Y}}{A}\right]^{r}(1-D)^{r-k} &
\end{array}
$$

The flow rules are obtained by deriving each potential with respect to the conjugated variables:

$$
\begin{aligned}
& {\underset{\sim}{\dot{\varepsilon}_{n}}}=\frac{\partial F_{n}}{\partial \underset{\sim}{\sigma}}=\left\langle\frac{\left\langle\sigma_{n}>/(1-D)-R_{n}\right.}{K_{n}}\right\rangle^{n_{n}}(1-D)^{-1} \underline{\mathbf{n}} \otimes \underline{\mathbf{n}}=\dot{\delta} \underset{\sim}{\mathbf{N}} \\
& \dot{\sim}_{t}=\frac{\partial F_{t}}{\partial \underset{\sim}{\sigma}} \quad=\left\langle\frac{|\tau| /(1-D)-R_{t}}{K_{t}}\right\rangle^{n_{t}}(1-D)^{-1}\{\underline{\mathbf{n}} \otimes \underline{\mathbf{t}}\}=\dot{\gamma} \underset{\sim}{\mathbf{T}} \\
& \dot{D}=\frac{\partial F_{d}}{\partial Y}=\left[\frac{(1-D) \sqrt{2 E Y}}{A}\right]^{r}(1-D)^{-k}=\left(\frac{\sigma_{d}}{A}\right)^{r}(1-D)^{-k}
\end{aligned}
$$

\subsection{Description of the environmental effect}

The real mechanism of iodine influence on the Zircaloy fracture is a complex mixture of physico-chemical effects. No clear opinion can be found in the literature, despite a considerable number of works dealing with SCC of Zircaloy in iodine environment [26][42][33] [43][44]. Among other mechanisms, weakening of Zr-Zr links is believed to happen, due to the iodine adsorption.

In the present approach, the impact of iodine will be simulated by a diffusion law, where diffusivity will strongly depend on damage. As a result, the amount of iodine will abruptly decrease in front of the crack tip in the 
grain boundary. Diffusion is allowed in grain boundaries, but is much less active in the core of the grain. The coupled calculation follows earlier works, like for instance [45]. The actual iodine profile will be influenced by mechanics, since the diffusion coefficient is damage dependent, meanwhile the mechanical result is influenced by the presence of iodine, since the material resistance described by the damage law depends on iodine concentration. A weak coupling method is used to account for the numerical coupling process. This method is a pre-existing tool of the code ZéBuLoN.

Iodine adsorption is then simulated by a classical Fick's laws:

$$
\begin{gathered}
\underline{\mathbf{J}}=\mathbf{D} \cdot \nabla C \\
\frac{\partial C}{\partial t}=\mathbf{D} \cdot \Delta C
\end{gathered}
$$

Here $C$ - concentration, $\mathbf{D}$ - diffusion coefficient, $\underline{\mathbf{J}}$ - material flux.

¿From a numerical point of view, the coupling is obtained by running two simultaneous problems, which are coupled at each time step. For each integration step, the diffusion problem is solved first. Iodine concentration is then exported to the mechanical problem to compute concentration dependent parameters. With these newly obtained parameters, the mechanical problem is solved. It provides stress, strain and damage fields. Damage is then exported to the diffusion problem, to compute damage dependent parameters, and recompute the same time step. For each time step, a fixed point algorithm is then introduced. The iterating scheme is stopped for a given value of the correction on concentration and on displacements, with a minimum of two (namely diffusion-mechanics-diffusion-mechanics).

\subsection{Identification process}

The mechanical material parameters can be divided into three groups:

- basic single crystal model parameters,

- parameters for the intergranular behaviour,

- transgranular fracture related parameters. 
Basic single crystal model. These parameters were identified for Zircaloy in a previous study [46], using a collection of tension tests at $350^{\circ} \mathrm{C}$ under various strain rates $\left(2 \cdot 10^{-3}, 2 \cdot 10^{-4}, 2 \cdot 10^{-5}, 2 \cdot 10^{-6}\right)$ and creep tests at various stress levels (275 MPa, $350 \mathrm{MPa}, 380 \mathrm{MPa}$ ). Isotropic hardening can be neglected, so that the remaining material parameters are $K, n$ for viscosity, $\tau_{0}$ for initial resolved shear stress, $c, d$ for the kinematic hardening law (table 1 ).

\begin{tabular}{|c|c|c|c|c|}
\hline Slip system & Prismatic & $\begin{array}{c}\text { Pyramidal } \\
\pi_{1}<a>\end{array}$ & Basal & $\begin{array}{c}\text { Pyramidal } \\
\pi_{1}<c+a>\end{array}$ \\
\hline$\tau_{0}(\mathrm{MPa})$ & 20. & 107. & 132. & 195. \\
\hline $\mathrm{K}\left(\mathrm{MPa} \cdot \mathrm{s}^{1 / n}\right)$ & 198. & 500 & 90. & 55. \\
\hline $\mathrm{n}$ & 9.5 & 7.5 & 5.5 & 11.3 \\
\hline $\mathrm{d}$ & 170. & & & 170. \\
\hline $\mathrm{c}(\mathrm{MPa})$ & 22100. & & & 6120. \\
\hline
\end{tabular}

Table 1: Basic single crystal model parameters for four slip system families in Zircaloy at $350^{\circ} \mathrm{C}$

Parameters for intergranular fracture. The identification of the parameters is made by considering successively the non-damaged material, then the damaged state.

- In the non-damaged state, it is well admitted that the propagation of iodine is non significant: for instance, the advance of a iodine front was found to be about $100 \mathrm{~nm}$ after a 16 hour test [28]. This allows us to choose the appropriate value for the diffusion coefficient for the initial state, $\mathbf{D}_{0}$. In fact, the inter-transgranular fracture process happens in about 10 minutes in a Zircaloy tube wall of $600 \mu \mathrm{m}$ width. Since intergranular a typical crack propagation rate is $0.1 \mu \mathrm{m} / \mathrm{s}$, and transgranular propagation rate remains between 1 and $20 \mu \mathrm{m} / \mathrm{s}$ [29], pure diffusion does not happen at all in the process. The diffusion coefficient $\mathbf{D}$ can then take any small value for the grains as well as for the grain boundaries (even if grain boundaries are usually known to have higher $\mathbf{D}$, than the grain core [47]). The chosen value in absence of damage is then $\mathbf{D}_{0}=2 \cdot 10^{-13} \mathrm{~mm}^{2} \mathrm{~s}^{-1}$.

If there is no iodine, damage should not happen during the computation time. This must be obtained by calibrating the material parameters in equation (15). To achieve this requirement, using prescribed values for $k$ and $r$, 
the value defined fo $A$ in absence of damage is such as it provides a damage of $10^{-5}$ after $1000 \mathrm{~s}$, with a typical stress value of $1000 \mathrm{MPa}$.

- In the damaged state, adsorption is known to happen faster, specially at grain boundaries. The parameter $\mathbf{D}$ is then damage dependent, and the parameter of the damage law $A$ is dependent on iodine concentration. This coupling can then be adjusted to obtain the target intergranular crack propagation rate. The calibration is made by performing preliminary computations involving diffusion only, with a value $\mathbf{D}_{0}$ in grain core and the target value in the grain boundaries. Two expressions of $\mathbf{D}$ will be used: $\mathbf{D}_{s}$ corresponds to slow $(s)$ damage rate, that will provide a crack propagation rate of $0.1 \mu \mathrm{m} / \mathrm{s}$, and $\mathbf{D}_{f}$ corresponds to fast $(f)$ damage rate, that predicts a higher rate (around $0.5 \mu \mathrm{m} / \mathrm{s}$ ), in order to get conservative results. They are listed in table 2 , together with the parameters representing intergranular fracture and the material parameter in the damage evolution equation, $A$ (unit is $\left.\mathrm{MPa} . \mathrm{s}^{1 / r}\right)$.

\begin{tabular}{ccccccccc}
\hline$R_{n}$ & $K_{n}$ & $n_{n}$ & $R_{t}$ & $K_{t}$ & $n_{t}$ & $\mathrm{k}$ & $\mathrm{r}$ & $\beta$ \\
$M P a$ & $\mathrm{MPa} \cdot s^{1 / n_{n}}$ & & $\mathrm{MPa}$ & $\mathrm{MPa} \cdot s^{1 / n_{t}}$ & & & & \\
900. & 200. & 8. & 900. & 200. & 8. & 3. & 4. & 0.01 \\
\hline $\begin{array}{l}A=1000+10^{5} e^{-12 C} \\
\mathbf{D}_{0}=2 \cdot 10^{-13} \mathrm{~mm}^{2} s^{-1}\end{array}$ & $\mathbf{D}_{s}=10^{-13}+4 \cdot 10^{-6}\left(1-e^{-12 D}\right)$ \\
\hline
\end{tabular}

Table 2: Material parameters for the DOS model (depending on iodine concentration, $C$ and damage, $D$ )

Transgranular fracture. Finally, cleavage is represented by a transgranular fracture model, which is nothing but an additional strain component that produces an extension normal to the basal plane (with a $\underline{\mathbf{n}} \otimes \underline{\mathbf{n}}$ tensor). This cleavage strain is supposed to appear only if the resolved stress on the cleavage plane becomes higher than a threshold $R_{c l}$. This threshold is also linked to the presence of iodine, that promotes the occurrence of cleavage. The effective value of $R_{c l}$ was chosen regarding the distribution of resolved cleavage stress for a preliminary aggregate computation without fracture, in order either to have a good chance to start the TG fracture at relatively small loadings $\left(R_{c l}=100+10^{5} \cdot e^{-20 \cdot C} \mathrm{MPa}\right)$, or to avoid the transgranular fracture, until preliminary intergranular crack is developed $\left(R_{c l}=1000+\right.$ $\left.10^{5} \cdot e^{-20 \cdot C} \mathrm{MPa}\right)$. 


\section{Results and discussion}

The aim of the various investigations is to check the relevance of the numerical model and to exhibit a configuration able to reproduce the different damage mechanisms.

\subsection{Outline of the numerical investigations}

As shown in Tab.3, different meshes have been considered, in order to check the effect of introducing linear or quadratic elements, regular or Voronoï type grain shapes, 2D or 3D geometries, coarse or fine discretization. The list of the related Finite Element Analyses is then given in Tab.4. Various fracture modes are considered: intergranular (IG), transgranular(TG) or both $(\mathrm{IG}+\mathrm{TG})$.

\begin{tabular}{|c|c|c|c|c|c|}
\hline $\begin{array}{c}\text { Mesh } \\
\text { label }\end{array}$ & Dim & $\begin{array}{c}\text { Grain } \\
\text { shape }\end{array}$ & $\begin{array}{c}\text { Grain } \\
\text { number }\end{array}$ & $\begin{array}{c}\text { Node } \\
\text { number }\end{array}$ & $\begin{array}{c}\text { Lin/ } \\
\text { Quad }\end{array}$ \\
\hline 100gr2D_1_noGB & 2D & Voronö̈ & 115 & 30551 & Quad \\
\hline 100gr2D_1 & 2D & Voronö̈ & 115 & 11818 & Lin \\
\hline 100gr2D_1quad & 2D & Voronoï & 115 & 48473 & Quad \\
\hline 100gr2D_2 & 2D & Voronoï & 100 & 37729 & Quad \\
\hline 100gr2D_3 & 2D & Voronö̈ & 100 & 37340 & Quad \\
\hline 20gr3D & 3D & Voronö̈ & 20 & 36114 & Lin \\
\hline 71gr2D & 2D & Voronö̈ & 71 & 19502 & Quad \\
\hline 71gr2Dhexa & 2D & Hexagonal & 71 & 19249 & Quad \\
\hline 100gr2Ddens4 & 2D & Voronö̈ & 100 & 13161 & Quad \\
\hline 100gr2Ddens2 & 2D & Voronö̈ & 100 & 37377 & Quad \\
\hline 100gr2Ddens1 & 2D & Voronö̈ & 100 & 125141 & Quad \\
\hline
\end{tabular}

Table 3: The finite element meshes used in the study

All computations are grouped into 4 sets, for several comparisons. Set 1 contains one computation without any GB (2DnoGB) in order to provide a reference in absence of damage. The rest of the analyses involve $2 \mathrm{D}$ and 3D computations, linear and quadratic meshes, and various damage types (IG, TG, IG+TG). The purpose is to evaluate the stability of the mechanical responses. Set 2, is given to show more details on the crack path and propagation rate depending on the aggregate morphology: it includes various 


\begin{tabular}{|c|c|c|c|c|}
\hline $\begin{array}{c}\text { Set } \\
\text { number }\end{array}$ & Notation & $\begin{array}{c}\text { Mesh } \\
\text { label }\end{array}$ & $\begin{array}{c}\text { Allowed } \\
\text { fracture } \\
\text { mode }\end{array}$ & $\begin{array}{c}\text { Diffusion } \\
\text { regime } \\
(\mathrm{s}, \mathrm{f})\end{array}$ \\
\hline \multirow{2}{*}{ 2DnoGB } & 100gr2D_1_noGB & - & - \\
& 2Dlin & 100gr2D_1 & - & - \\
& 2Dquad & 100gr2D_1_quad & - & - \\
& 2DIG & 100gr2D_1 & IG & $\mathrm{s}, \mathrm{f}$ \\
& 2DIGTG & 100gr2D_1 & IG+TG & $\mathrm{s}$ \\
& 3DIG & 20gr3D & IG & $\mathrm{s}$ \\
\hline 2 & 2DIG2 & 100gr2D_2 & IG & $\mathrm{f}$ \\
& 2DIG3 & 100gr2D_3 & IG & $\mathrm{f}$ \\
& 2DTG2 & 100gr2D_2 & TG & $\mathrm{f}$ \\
& 2DTG3 & 100gr2D_3 & TG & $\mathrm{f}$ \\
& 2DIGTG3 & 100gr2D_3 & IG+TG & $\mathrm{f}$ \\
\hline 3 & 71gr2DIGhexa & 71gr2Dhexa & IG & $\mathrm{f}$ \\
& 71gr2DIG & 71gr2D & IG & $\mathrm{f}$ \\
\hline 4 & 2DIGdens4 & 100gr2Ddens4 & IG & $\mathrm{f}$ \\
& 2DIGdens2 & 100gr2Ddens2 & IG & $\mathrm{f}$ \\
& 2DIGdens1 & 100gr2Ddens1 & IG & $\mathrm{f}$ \\
\hline
\end{tabular}

Table 4: Outline of the finite element analyses

100 grain aggregate in $2 \mathrm{D}$, with various damage types. In set 3 , only two computations are present: the aim is to compare the effect of a regular grain structure made of hexagons and of the random Voronoï polyhedra morphology. Finally, set 4 is designed with three meshes having an equivalent grain geometry, but different finite element mesh density, in order to check the effect of mesh density.

\subsection{Global force-displacement curves}

Five computation cases in set 1 are first compared to test the validity of the procedure. The relating curves are presented in Fig.7a. The "slow" value $\mathbf{D}_{s}$ is chosen for the diffusion coefficient. Various models are considered for the grain boundaries and various element types are used:

1. the grain boundaries have the properties of the attached crystal, a linear interpolation is used in finite elements (2Dlin); 
2. the grain boundaries have the properties of the attached crystal, a quadratic interpolation is used in finite elements (2Dquad);

3. the mesh does not include any grain boundary (2DnoGB), quadratic interpolation;

4. iodine influence is taken into account in a 2D mesh (2DIG), intergranular damage only;

5. iodine influence is taken into account in a 3D mesh (3DIG), intergranular damage only;

6. iodine influence is taken into account in a 2D mesh (2DIGTG), intergranular damage and transgranular damage.

As expected, the computation made with a linear mesh (1) predicts a stiffer response than the computation with a quadratic mesh (2). On the other hand, the reference curve without grain boundaries (3) does not differ from the curve obtained with grain boundaries (2). This is a validation of the approach: in absence of damage, opening and shear, grain boundary elements are nothing but classical elements, with the relevant single crystal constitutive equations. Iodine effect is sensitive when the strain is larger than 1\%. The corresponding curves exhibit softening. The 2D computation (4) and the 3D computation (5) were done with the same material parameters. The softening is more pronounced in the $3 \mathrm{D}$ computation. This is due to the smaller size of the 3D mesh: the grain size is comparable in the $2 \mathrm{D}$ and $3 \mathrm{D}$ mesh, but there is a low number of grains in the $3 \mathrm{D}$ mesh, in order to have a reasonable number of finite elements. As a consequence, the edge length of the $3 \mathrm{D}$ mesh is $30 \mu \mathrm{m}$, meanwhile it is $100 \mu \mathrm{m}$ for the $2 \mathrm{D}$ mesh. With the same crack length, the force drop is then larger for the 3D mesh. In addition, the 3D mesh is far from being a statistically representative material element and the computation is sensitive to boundary conditions. For all these reasons, 2D computations are considered as the more reliable in the present state.

The estimation of the crack propagation rate for the intergranular case is obtained by plotting the maximum abscissa of an integration point with an elevated damage value $(>0.9)$ as a function of time. This is made for $2 \mathrm{DIG}$ and 3DIG in Fig.7b: the model calibration is in rather good agreement with the crack propagation rate of $0.1 \mu \mathrm{m} / \mathrm{s}\left(\right.$ with $\left.\mathbf{D}_{s}\right)$.

\subsection{Intergranular crack propagation}

A first set of computations involves pure intergranular crack propagation only, for 2D (2DIG computation, in Fig.8) and 3D (3DIG computation, in 
Fig.9) cases. For both computations, crack initiation is promoted by iodine and takes place at the free surface, then cracks propagate into the bulk of the material. The contour plots of the damage variable characterize crack advance. For the 2D case (Fig.8), after a first stage where several cracks initiate, one of them becomes predominant, and crosses the aggregate. This main crack has a zigzag-shape, imposed by grain boundaries, but it tends to keep an average horizontal direction, normal to the vertical tensile axis. The crack produces a local unloading that can be observed on the von Mises stress maps. Crack branching is present at triple points. In fact, there is an "hesitation" of the main crack each time it reaches such a point. After a certain delay due to the mutual unloading between the two branches, one branch becomes predominant and the alternative branch is stopped.

For the 3D case (Fig.9), the crack also initiates at the iodine influenced surface of the aggregate. The first affected grain boundary is perpendicular to the tensile axis. At first, the zone affected by stress relaxation presents a typical elliptic shape. In a second step, this zone extends to the whole iodine influenced surface. The general crack path also tends to be normal to the tension direction.

The results on different aggregate morphologies (71gr2DIG, 2DIG2 and 2DIG3) in Fig.10) show the various possible crack configurations. The general direction of crack propagation is normal to the tensile axis, but some noticeable deviations can be produced by the local crystallography. This is observed on both types of shapes (Voronoï tessellation and hexagonal grains).

After having checked that the qualitative aspect of the cracks is similar in all the analyses, the crack propagation rate is also evaluated, to provide a quantitative view of the phenomenon. Following the procedure presented for Fig.7b, the new results are now shown in Fig.11. Despite the different crack geometries, the result obtained with the regular hexagonal grain shape (71gr2DIGhexa) does not differ too much from the curve obtained with the various random Voronoï polyhedra generations, the rectangle shape 71gr2DIG, and the three different Voronoï tessellations of a 100 grain 2D aggregate, 2DIG, 2DIG2 and 2DIG3. The parameters of the model are also in agreement with the results previously shown in Fig.7b. This is an encouraging result, that confirms the validity of the whole approach.

The way the results depend on mesh density has to be checked. A set of computations was then done to investigate this effect and validate the preceding solutions, with three meshes of equivalent grain geometry but increasing finite element mesh density (2DIGdens4, 2DIGdens2, 2DIGdens1). A qual- 
itative and a quantitative post-processing are performed. Figure 12 shows that the crack path obtained for the coarse mesh (2DIGdens4) differs from the paths obtained with the two other meshes, even for the early stages of fracture. Surprisingly, this qualitative difference produces no marked quantitative differences on the global load deflection curve (Fig.13a) and on the crack propagation rate (Fig.13b). On the other hand, for the two finer meshes (2DIGdens2 and 2DIGdens1), the crack paths are the same, but there are differences on the loading curve and the crack propagation rates: in fact, they are both in good agreement for the early stages of the fracture (up to $100 \mathrm{~s}$, that is a depth of 3 grains). A difference happens, when the crack meets a grain boundary that is nearly parallel to the tensile direction, i.e. not favourable to crack propagation. Along this small edge, the local difficulty is overcome by the coarser meshes, but the crack propagation rate is smaller for the finer mesh (2DIGdens1). After this "accident", the crack propagation rate is again the same for all the curves. In other words, the results tend to converge for the GB nearly perpendicular to the tensile direction (and thus favorably oriented for fracture), but the use of coarse meshes tend to over-estimate the crack propagation rate, since large elements produce fast crack propagation in the critical zones.

\subsection{Transgranular crack propagation}

Before investigating the realistic inter-transgranular crack propagation, the conditions of an hypothetic purely transgranular crack propagation is first studied, in order to better understand the possibilities of the approach. The effective cleavage limit is temporary chosen quite low, to ensure the transgranular crack initiation from the beginning of the loading. 2D computations are then done, for two random realizations of a 100 grain aggregate: 2DTG2 and 2DTG3. The transgranular crack propagation is represented by the development of the cleavage pseudo-strain. As cleavage happens in basal plane, the presence of cleavage is strongly influenced by the basal plane orientation, compared to the tensile direction. The crystal orientation is defined by the Euler angles in Bunge notation, $\left(\phi_{1}, \Phi, \phi_{2}\right)$. The first and the third rotations are around the $c$ axis of the hexagonal crystal, so that they do not change the position of the basal plane. That is why, the maps of $\Phi$ angle are presented in Fig.14. One can observe that the grains affected by transgranular fracture tend to have $\Phi$-values of about 90 degrees, that naturally give the basal plane perpendicular to the tension direction. On the other hand, the grains with

$\Phi$-values not far from zero seem to be avoided by the crack. The question of 
crack propagation rate is more delicate here, than for the intergranular case, due to the nature of the approach itself. The intergranular fracture process is described by its own variable, damage, that follows prescribed constitutive equations, and that can be controlled by specific material parameters. On the other hand, for cleavage, nothing happens, until the stress state reaches the limit $\mathrm{R}_{\text {cleav }}$. One can follow the crack propagation by plotting the maximum abscissa of all the integration points that reach a given cleavage strain as a function of time. This is made with a threshold of 0.01 in Fig.11. Different microstructures give surprisingly similar results, just as for the intergranular case. As experimentally found, the transgranular crack propagation is faster than intergranular crack propagation. Of course, this last result may depend on the chosen threshold.

\subsection{Inter-Transgranular passage}

The full model is now used in this section. This means that both mechanisms of fracture, inter- and transgranular are taken into account in the same computation. Several computations were made, as mentioned in Tab.4. The selected diffusion type is $s$. Figure 15 shows that this parameter may affects not only crack propagation rate, but also the crack path, since several cracks are initiated by the intergranular damage model, unlike $f$ model, that produces one predominant crack (Fig.8). One can even see one grain that seems to be totally disconnected from the rest of the aggregate: this is an artefact due to the damage threshold chosen for the elimination of the grain boundary elements. Depending on the way transgranular damage is added, the post-intergranular scenario can change. In Fig.15a, the cleavage threshold value is constant $(1000 \mathrm{MPa})$. Transgranular damage appears far ahead of the crack, in grains that are reloaded due to stress redistribution when the crack propagates. This spurious effect is avoided, provided the cleavage threshold is affected by iodine concentration. This is the case in Fig.15b, where $R_{c l}=1000+10^{5} \cdot e^{-20 \cdot C}$. In this case, the addition of transgranular damage leads to new crack morphologies, as it offers new possibilities for the crack to propagate: the inter-transgranular transition may happen at a triple point or in the middle of an edge (respectively points $A$ and $B$ in Fig.15b).

Transition at triple points. After an intergranular propagation corresponding to several grains, it may happen that the intergranular crack meets a triple point, the two edges of which are not favourably oriented for intergranular cracking (case $A$ ). This case was observed in Fig.1b, where crack 
goes directly across the grain, that offers less resistance than the two grain boundaries. The simulation allows us to find the same phenomenon, as illustrated in Fig.16, which reports the results obtained with the 100gr2D_1 mesh. Figure 16a shows the position of the crack at the critical triple point. Figure 16b illustrates the result obtained in the 2DIG computation, where only intergranular damage is present: one of the two critical edges is finally "chosen" by the crack. On the other hand, if the cleavage model is introduced (Fig.16c), the crack becomes transgranular. In these figure, damage is illustrated by means of a special post-processing: the new variable combines intergranular and transgranular damages by computing the sum of intergranular damage and 100 times the cleavage strain. The crack rate is compared for the two cases in Fig.16d. The propagation is a little slower for the 2DIGTG case, as long as it remains intergranular. This is due to the fact that a little cleavage pseudo-strain develops in the aggregate. As expected, when the crack becomes transgranular, the propagation rate increases.

The subsequent behaviour of a transgranular crack may be either transgranular or intergranular. The contour plot in Fig.17 is obtained with the 100gr2D_3 mesh, in the computation 2DIGTG_3. After crossing a grain whose two edges are not favourably oriented at a triple point, the crack becomes intergranular, as it meets the other side of the grain in the vicinity of a grain boundary that is perpendicular to the tensile axis.

Transition in the middle of an edge. An other transition type is also observed, when the two grains adjacent to an intergranular crack are too different (case $B$ ). As seen in Fig.18, this simulation reproduces the experimental observation made by [30] and reproduced in Fig.1c. Grain noted (1) in Fig.1c (gr59 in the computation) is preferably oriented for prismatic or basal slip, meanwhile grain noted 2 (gr53 in the computation) has little prismatic+basal slip, but a predominant pyramidal slip. This is the proof that grain 2 hardly deforms. The alternative solution to accommodate the general deformation is then crack opening. This is observed in grain 2 (the crack denoted 3 develops in the basal plane).

Discussion of the mechanisms. The use of stress as a critical variable for both intergranular damage and transgranular fracture captures the main aspects of the inter-transgranular transition. Both mechanisms remain in competition, so that the passage from inter to transgranular mode is not definitive. In our simulations, transgranular cracks always start from a pre-existing intergranular crack. They can have their origin at a triple point, each time the 
two outcoming edges are not favourably oriented, or in the middle of grain boundary, each time the amount of slip differs too much on both sides of the intergranular crack. This second mechanism is promoted by the fact that iodine adsorption is promoted by plastic strain [42]: when one grain on one side of the intergranular crack presents intensive prismatic slip, transgranular initiation can be predicted in the opposite grain due to overstress, or after intensive secondary slip, followed by iodine adsorption that locally decreases the cleavage threshold. Such a fact is classical for zinc single crystal [48], where cleavage in basal plane is accompanied by intensive basal slip. Such an approach would naturally explain the observations on pre-deformed specimens that tend to exhibit more TG fracture - [43] or the fact that TG failure comes earlier in pre-stressed tubes than in annealed ones - [49].

When the crack becomes transgranular, it may lead to a rapid transgranular failure, but a sequence $\mathrm{IG} \rightarrow \mathrm{TG} \rightarrow \mathrm{IG}$ can also be found. Such a sequence has been reported in earlier works [22] or experimental data [50].

\subsection{Discussion of the approach for the grain boundary modeling}

The strategy used for representing grain boundaries does not use cohesive zone models. The latter solution could be justified by the fact that grain boundaries are two-dimensional defects of the crystal network [51], with the thickness of 2-3 atom size. Nevertheless, the present approach introduces a classical finite element, that is a layer of finite thickness with specific properties that represents a "grain boundary affected zone". Both strategies are equivalent when the thickness of the real element tends to zero [9]. The present strategy may present a few advantages:

- since only classical finite elements are used, the already developed numerical methods and material models can be directly applied;

- the newly developed finite element mesh family with the grain boundary network is available for application to other problem types, like real interphases or GB segregation;

- the grain boundary element provides a rather precise evaluation of the stress and strain fields in the real vicinity of the grain boundary, with a different material in each grain. 


\section{Conclusion and perspectives}

A coupled mechanics-environment approach of grain boundary damage, opening and sliding was presented here, as an extension of the classical crystal plasticity formalism. The phenomenon of environmentally assisted intertransgranular cracking was successfully represented. The agreement between the numerical simulation and the experiment is fairly good. The crack path follows grain boundaries when the crack length is not longer than a few grains. The propagation rate is affected by triple points: each time a triple point is reached, crack branching appears after an "hesitation" period. The result is a main crack with a series of small branches that have been stopped after a very small propagation. On the other hand, triple point may be the origin of transgranular cracks: the approach captures the intergranular-transgranular transition, when after intergranular propagation, the crack becomes transgranular, due to the activation of a cleavage mechanism. Being able to predict the transition point and the subsequent behaviour is an important practical problem, since the crack propagation rate changes dramatically when the regime remains transgranular.

In the model, failure is represented by a combination of a damage mechanics approach for intergranular rupture (that is caused by cavity nucleation and growth), and of a viscoplastic law with softening (negative hardening) for cleavage (that is a splitting of the crystal along a basal plane, when the stress level exceeds a critical threshold). The parameter identification procedure consists in two steps. The first one, and the most important, deals with intergranular failure. On the other hand, transgranular failure happens when intergranular failure meets bad propagation conditions. The identification of the second part of the model is then linked to the first one, and cannot be performed independently.

In the field of SCC, a series of conditions are known to be important [52]: strain-stress state conditions; metallurgical data (texture, morphology, impurities, composition); mechanical properties; corrosive environment parameters (chemical composition, $\mathrm{pH}$, temperature, electrochemical potential). The effect of these parameters can be taken into account by the model:

- up to now, only monotonous tensile loadings were applied in the simulations, but there is no difficulty to apply any other stress state, like creep or cyclic loading;

- the impact of crystallographic texture can be considered, since the grain 
morphology is explicitly involved into the model. For the present computations equiaxial convex grains were used, as it is the case for the recrystallized state of Zircaloy-4. Elongated grains, structures with large grains embedded into a matrix made of smaller grains, structures with a large amount of twins, etc... could be used in the computations;

- the parameters of the model, corresponding to the initial state without damage were identified for the temperature of $350^{\circ} \mathrm{C}$ on a collection of tension and creep tests. The mechanical properties play an important role in the damage process. Other temperatures could be characterised as well;

- the main limitation in the model is the fact that the corrosive environment parameters are just taken into account by a phenomenological approach, so that neither chemical nature, nor acidity or electrochemical potential of the environment are directly involved into the model. The only parameter, responsible for the environment is the equivalent diffusion coefficient, and it must be calibrated on experimental results.

The strategy of weak coupling allows to easily introduce new features in the model, either on the mechanical or on the environmental part of the model. In the future, computation time is still to be improved, specially for 3D computations (parallel computing). In the same time, the stress and strain fields near the crack tip have to be carefully checked. Remeshing procedures could be introduced. Finally, the physical part of the model could be improved, by considering the real physical mechanisms. Anyway, under the present form, the model is already a powerful tool, able to represent the dependence of the crack propagation rate on temperature, and environment [29].

\section{References}

[1] Dugdale DS. Yielding of sheets containing slits. J. Mech. Phys. Sol. 1960;8:100.

[2] Barenblatt GI. The mathematical theory of equilibrium of cracks inbrittle fracture. Advances in Applied Mech. 1962;7:55.

[3] Needleman A. A Continuum Model for Void Nucleation by Inclusion Debonding. J. of Applied Mechanics. 1987;54:525. 
[4] Tvergaard V. Effect of Fiber Debonding in a Whisker-Reinforced Metal. Material Science and Engineering. 1990;125:203.

[5] Allix O, Ladevèze P. Interlaminar Interface Modeling for the Prediction of Laminate Delamination. J. Compos. Struct.. 1992;22:235.

[6] Michel Jean-Claude, Suquet Pierre, Thebaud Frederic. Ine modlisation du role des interfaces dans le comportement des composites matrice mtallique. Revue europenne des lments finis. 1994;3:573.

[7] Chaboche J L, Girard R, Schaff A. Numerical analysis of composite systems by using interphase/interface models. Computational Mechanics. 1997;20:3.

[8] Chaboche J-L, Feyel F, Monerie Y. Interface Debonding Models: a Viscous Regularization with a Limited Rate Dependency. Int. J. Solids Structures. 2001;38:3127.

[9] Suquet PM. Discontinuities and Plasticity. In: Nonsmooth mechanics and applications (Moreau JJ, Panagiotopoulos PD. , eds.)(Springer,Berlin):1987, p.280.

[10] Lebon F, Rizzoni R, Ronel-Idrissi S. Asymptotic analysis of some nonlinear soft thin layers. Computers \& Structures. 2004;82:1929.

[11] Mishuris G, Ochsner A. Transmission conditions for a soft elasto-plastic interphase betweentwo elastic materials. Archives of Mechanics. 2004.

[12] Lemaitre J. A course of Damage Mechanics. Springer Verlag 1996.

[13] Anand L. Single-crystal elasto-viscoplasticity: application to texture evolution in polycrystalline metals at large strains. Computer Methods in Applied Mechanics and Engineering. 2004;193:5359.

[14] Evers LP, Parks DM, Brekelmans WAM, Geers MGD. Crystal plasticity model with enhanced hardening by geometrically necessary dislocation accumulation. Journal of the Mechanics and Physics of Solids. 2002;50:2403.

[15] Jivkov AV, Stevens NPC, Marrow TJ. A two-dimensional mesoscale model for intergranular stress corrosion crack propagation. Acta Mat.. 2006;54:3493. 
[16] Jivkov AV, Stevens NPC, Marrow TJ. A three-dimentional computational model for intergranular cracking. Computational Materials Science. 2006;38:442.

[17] Barbe Fabrice, Decker Luc, Jeulin Dominique, Cailletaud Georges. Intergranular and intragranular behavior of polycrystalline aggregates Part 1: model. International Journal of Plasticity. 2001;17:513.

[18] Barbe Fabrice, Forest Samuel, Cailletaud Georges. Intergranular and intragranular behavior of polycrystalline aggregates Part 2: Results. International Journal of Plasticity. 2001;17:537.

[19] Kamaya M, Ikatura M. Simulation for intergranular stress corrosion cracking based on three dimensional polycrystalline models 2009 .

[20] Watanabe T. An approach to grain boundary design for strong and ductile polycrystals. Res Mechanica. 1984;11:47.

[21] Watanabe T, Tsurekawa S. The control of bittleness and develipment of desirable mechanical properties in polycrystalline systems by grain boundary engineering. Acta Metallurgica. 1999;47:4147.

[22] Lim LC, Watanabe T. Grain boundary character distribution controlled toughness of polycrystals A two-dimensional model. Scripta Metallurgica. 1989;23:489.

[23] Lim LC, Watanabe T. Fracture toughness and brittle-ductile transition controlled by grain boundary character distribution (GBCD) in polycrystals. Acta Metallurgica et Materialia. 1990;38:2507.

[24] Féron D, Olive J-M., eds. Corrosion issues in light water reactors. Woodhead Publishing 2007.

[25] Mori G, Scherer D, Schwentenwein S, Warbichler P. Intergranular stress corrosion cracking of copper in nitrite solutions. Corrosion Science. 2005 .

[26] Cox B. Pellet-clad interaction ) failures of zirconium alloy fuel cladding - review Journal of Nuclear Materials. 1990;172:249.

[27] Sidky PS. Iodine stress corrosion cracking of Zircaloy reactor cladding: iodine chemistry (a review). Journal of Nuclear Materials. 1998;256:1. 
[28] Fregonese Marion. Mécanismes de corrosion sous contrainte par l'iode dans le Zirconium et le Zircaloy-4 Transposition aux conditions d'interaction pastille-gaine dans les réacteurs à l'eau pressurisée. $\mathrm{PhD}$ thesisEcole des Mines de Saint-Etienne 1997.

[29] Farina S B, Duffo G S, Galvele J R. Stress corrosion cracking of zirconium and Zircaloy-4 in halide aqueous solutions. Corrosion Science. 2003;45:2497.

[30] Kubo T, Wakashima Y, Amano K, Nagai M. Effects of crystallographic orientation on plastic deformation and initiation of zirconium alloys. Journal of Nuclear Materials. 1985;132:1.

[31] Knorr D B, Pelloux RM. Effects of Texture and Microstructure on the Propagation of Iodine Stress Corrosion Cracks in Zircaloy. Metallurgical Transactions of ASM. 1982;13A:73.

[32] Woo Seog Ryu, Young Hwan Kang, Jai-Young Lee . Effects of iodine concentration on iodine-induced stress corrosion cracking of zircaloy-4 tube. Journal of Nuclear Materials. 1988;152:194.

[33] Duffo G S, Farina S B. Diffusional control in the intergranular corrosion of some hcp metals in iodine alcoholic solutions. Corrosion Science. 2005.

[34] Haddad RE, Dorado AO. Grain-by-grain study of the mechanisms of crack propagation during iodine stress corrosion cracking of Zircaloy-4. In Zirconium in the nuclear industry Tenth Int Symposium ASTM STP 1245(Philadelphia):1994, p.559.

[35] Miura H, Sakai T, Otsuka T, Monzen R, Onaka S. Sliding of copper [001]twist grain boundaries detected by shear deformation of liquid B2O3 particles on the grain boundaries. Acta Materialia. 2000;48:1959.

[36] Decker L, Jeulin D. Simulation 3D de materiaux aleatoires polycristallins La Revue de Metallurgie-CIT. 2000;96:271-275.

[37] Diard O, Leclercq S, Rousselier G, Cailletaud G. Evaluation of finite element based analysis of 3D multicrystalline aggregates plasticity: Application to crystal plasticity model identification and the study of stress and strain fields near grain boundaries. Int. J. of Plasticity. 2005;21:691. 
[38] Cailletaud G. A Micromechanical Approach to Inelastic Behaviour of Metals. IntJPlast. 1991;8:55.

[39] Méric L, Poubanne P, Cailletaud G. Single crystal modeling for structural calculations, Part 1 and 2. J of Eng Mat Tech. 1991;113:162.

[40] Musienko A, Tatschl A, Schmidegg K, Kolednik O, Pippan R, Cailletaud G. Three-dimensional finite element simulation of a polycrystalline cop per specimen. Acta Mat. 2007.

[41] Onck Patrick, Giessen Eric. Microstructurally-based modelling of intergranular creep fracture using grain elements. Mech. of Materials. 1997;26:109.

[42] Jacques Patrick, Lefebvre Florence, Lemaignan Clement. Deformationcorrosion interactions for $\mathrm{Zr}$ alloys during crack initiation: Part I: Chemical contributions. Journal of Nuclear Materials. 1999;264:239.

[43] Fregonese Marion, Olagnon Christian, Godin Nathalie, Hamel Alain, Douillard Thierry. Strain-hardening influence on iodine induced stress corrosion cracking of Zircaloy-4. Journal of Nuclear Materials. 2008;373:59.

[44] Park Sang Yoon, Kim Jun Hwan, Lee Myoung Ho, Jeong Yong Hwan. Effects of the microstructure and alloying elements on the iodine-induced stress-corrosion cracking behavior of nuclear fuel claddings. Journal of Nuclear Materials. 2008;376:98.

[45] Rabotnov YuN. O vozmozhnom mehanizme razrusheniya metalla v korrozionnoy srede (Concerning possible mechanism of metall fracture in corrosive environement). Izv Acad Nauk SSSR OTN. 1954;4:53.

[46] Diard O, Leclercq S, Rousselier G, Cailletaud G. Distribution of normal stress at grain boundaries in multicrystals: application to an intergranular damage modeling. Computational Materials Science. 2002;25:73.

[47] Mishin Y, Herzig Chr. Grain boundary diffusion: recent progress and future research. Materials Science and Engineering A. 1999;260:55.

[48] Gilman JJ. Mechanism of Ortho King-Band Formation in Compressed Zinc Monocrystals. Trans AIME, Journal of Metals. 1954:621. 
[49] Une Katsumi. Stress Corrosion Cracking of Zircaloy-2 Cladding in Iodine Vapor. J of Nuclear Sci and Tech. 1977;14:443.

[50] Fregonese M, Lefebvre F, Lemaignan C, Magnin T. Influence of recoilimplanted and thermally released iodine on I-SCC of Zircaloy-4 in PCIconditions: chemical aspects. J. Nucl. Mat. 1999;265:245.

[51] Priester L. Les joints grains De la théorie à l'ingénierie. EDP Sciences 2006.

[52] Konakova MA, Teplinskiy YuA. Stress Corrosion Cracking of Pipe Steels (Korrozionnoe rastreskivanie pod naprjazheniem trubnyh stalej). Info-da 2004. 


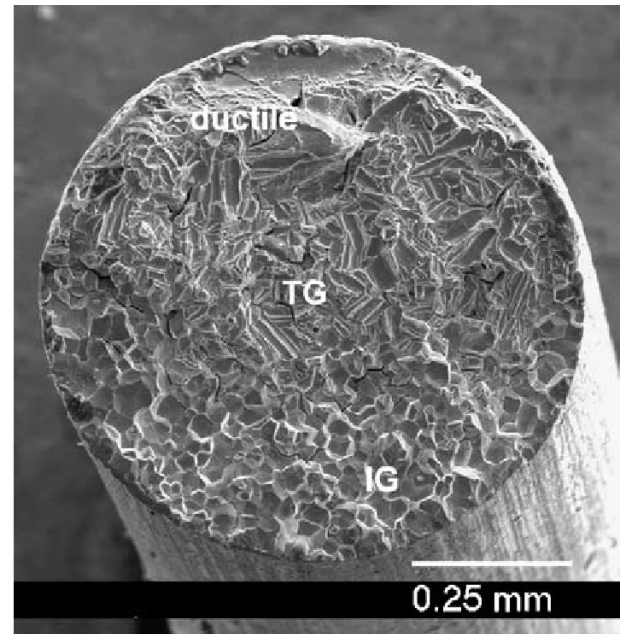

(a)

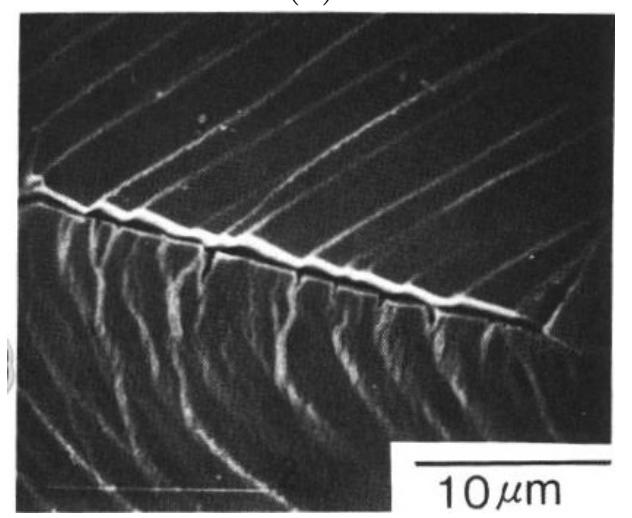

(c)

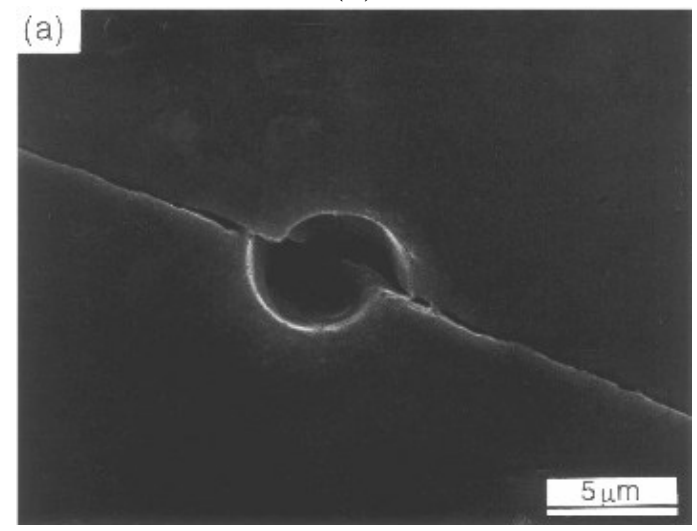

(e)

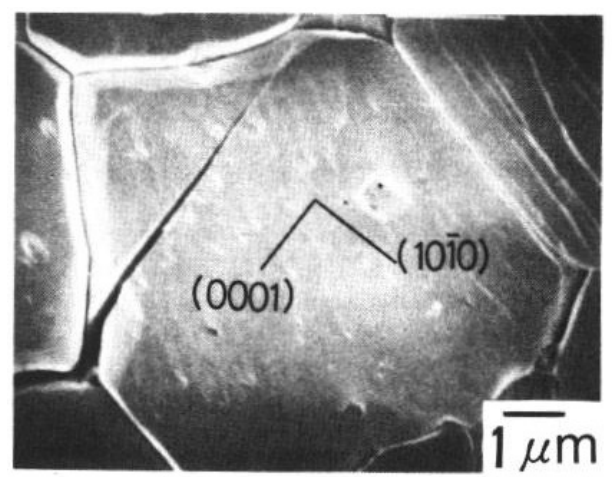

(b)

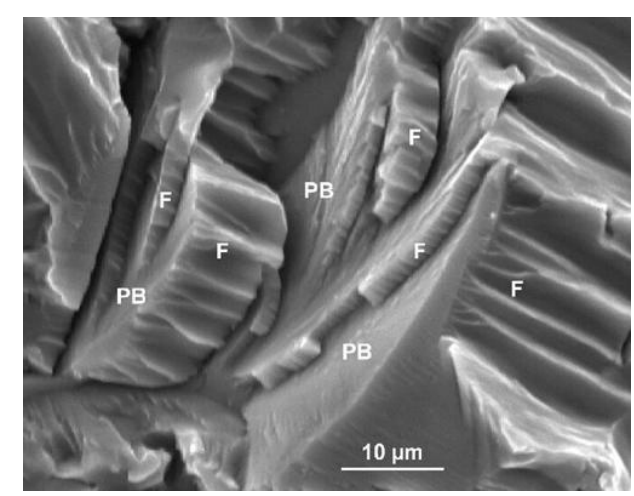

(d)

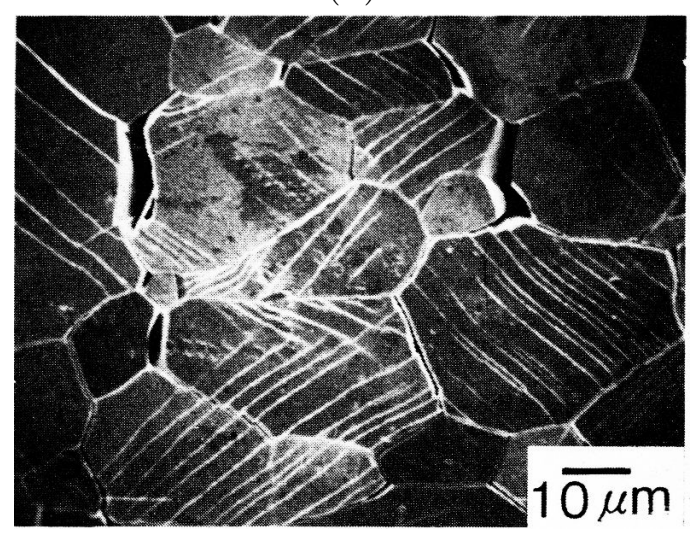

(f)

Figure 1: Available experimental data on Zircaloy-4 fracture in iodine environment: (a) Intergranular, transgranular, ductile fracture [29], (b) TG crack pictures [30],(c) TG crack initiation [30], (d) Details of TG crack propasetion [29], (e) Experimental evidence of grain boundary sliding in copper, [35], (f) Intergranular stress corrosion cracking, Zircaloy-2 in iodine, $[30]$ 


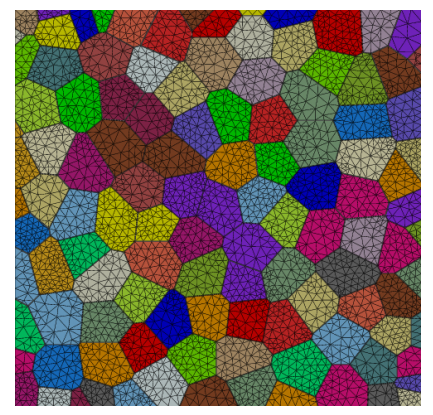

(a) 100gr2D_1

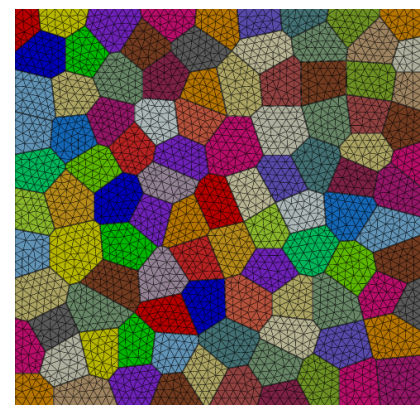

(b) 100gr2D_2

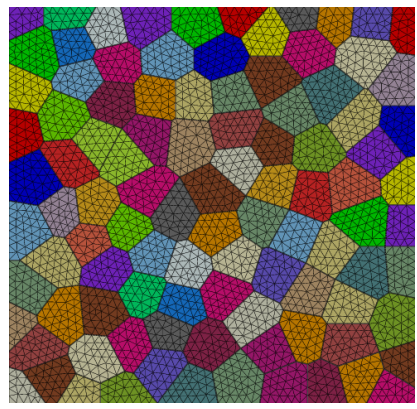

(c) 100gr2D_3

Figure 2: 2D mesh collection

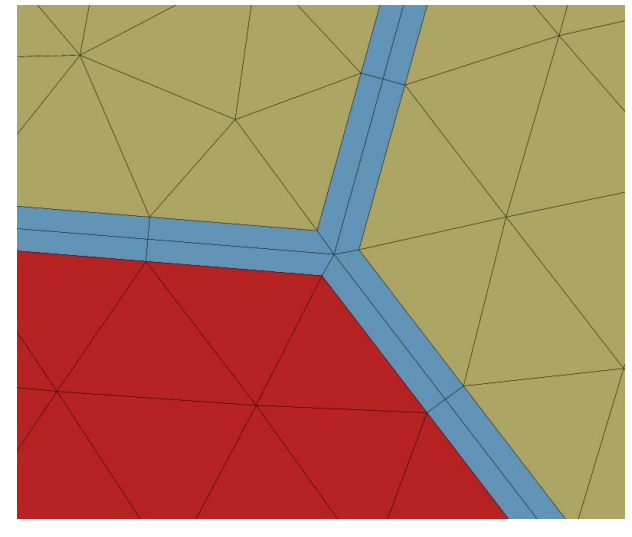

(a)

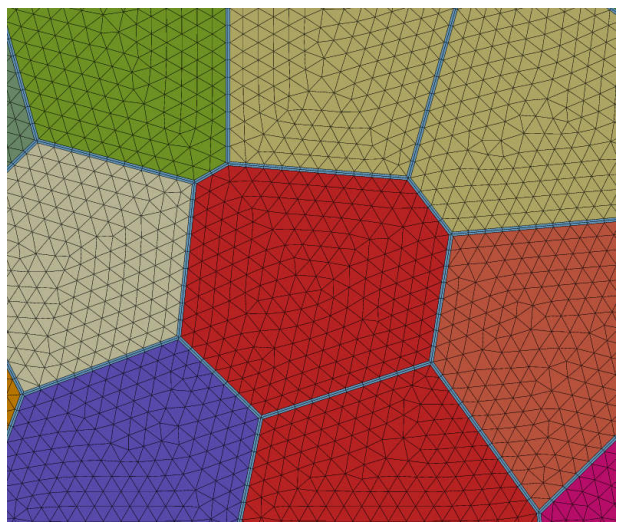

(b)

Figure 3: 2D meshing details 


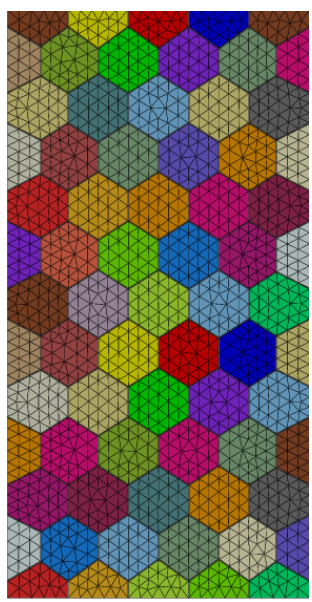

(a) 71gr2Dhexa

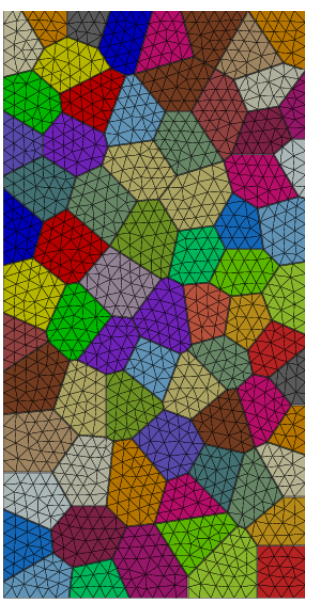

(b) $71 \operatorname{gr} 2 \mathrm{D}$

Figure 4: Examples of two 2D meshes with 71 grains: (a) regular hexagonal structure; (b) structure based on a Voronoï tessellation
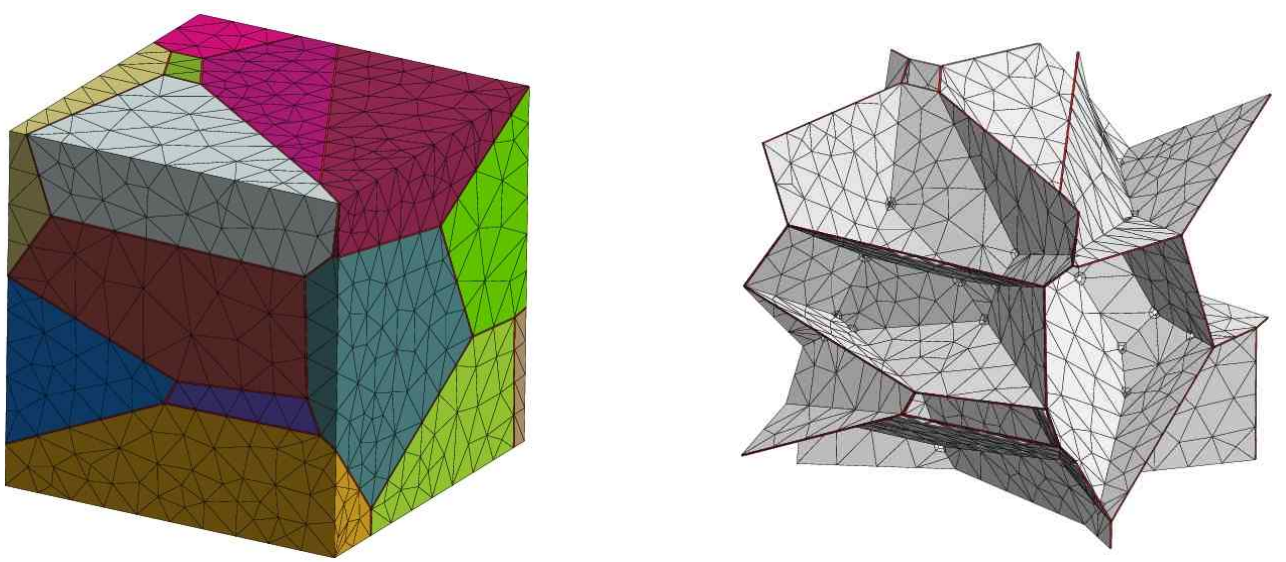

Figure 5: 3D finite element mesh with grain boundaries, left - outside view of the 20-grain aggregate, right - GB only for the same aggregate 

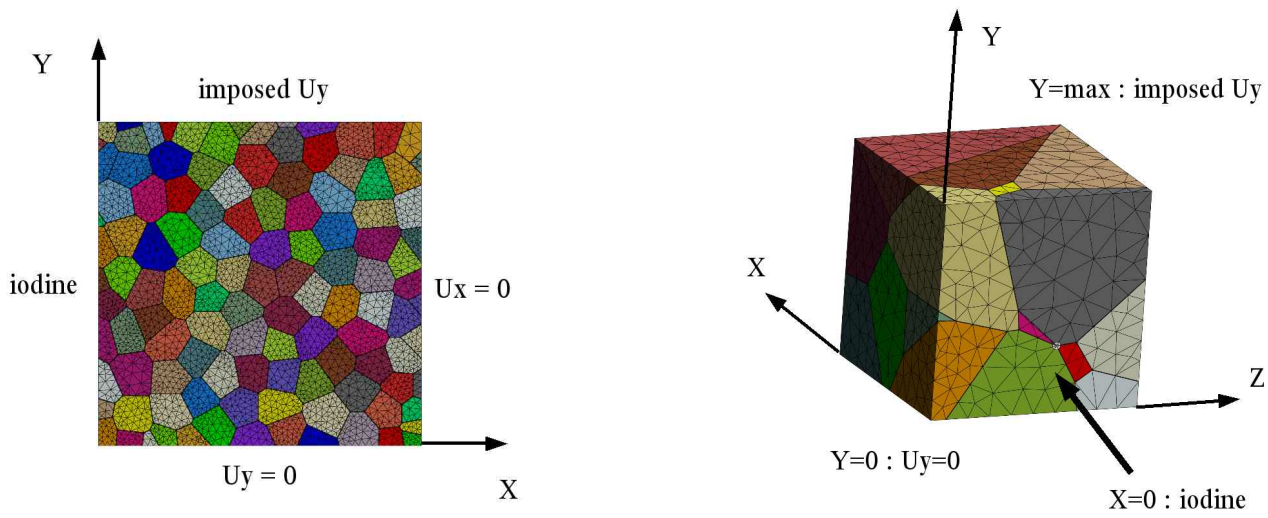

Figure 6: Boundary conditions for 2D and 3D computations

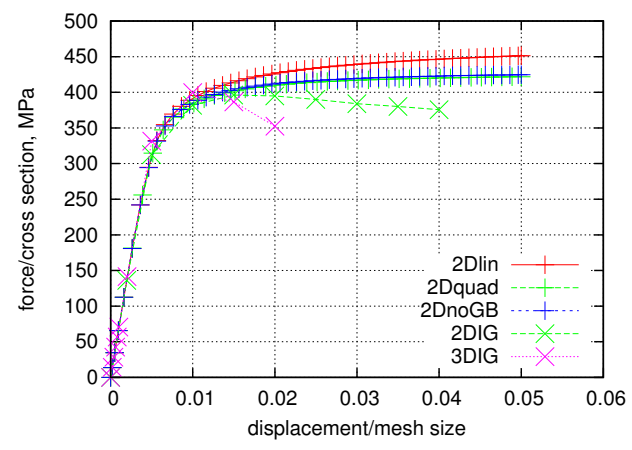

(a)

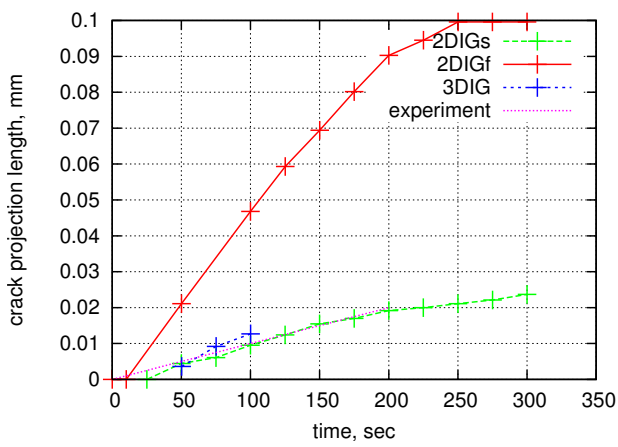

(b)

Figure 7: Global and local responses for various meshes in SCC simulations involving the DOS model: (a) Stress-strain curves; (b) Crack length as a function of time 


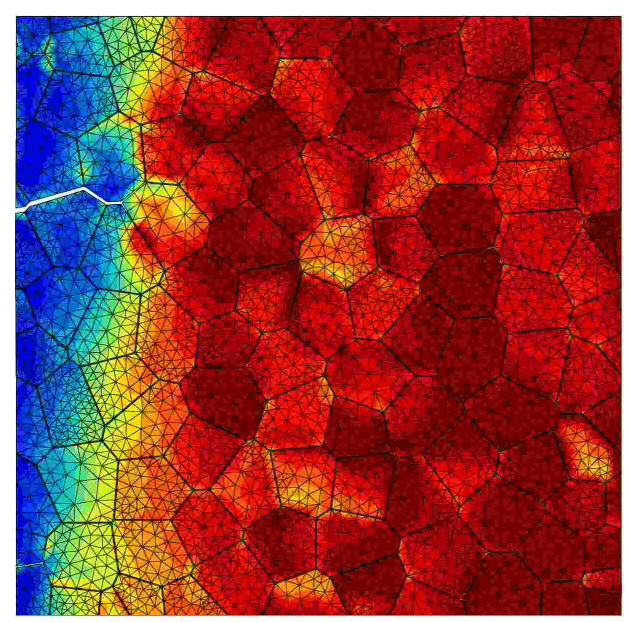

(a)

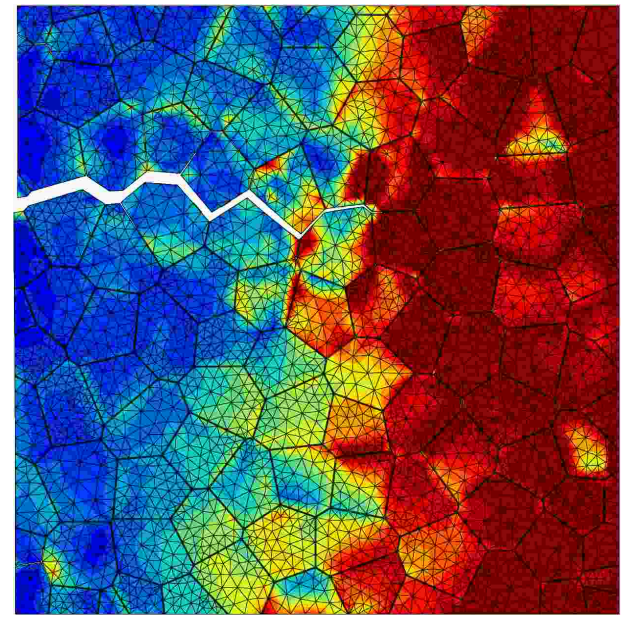

(c)

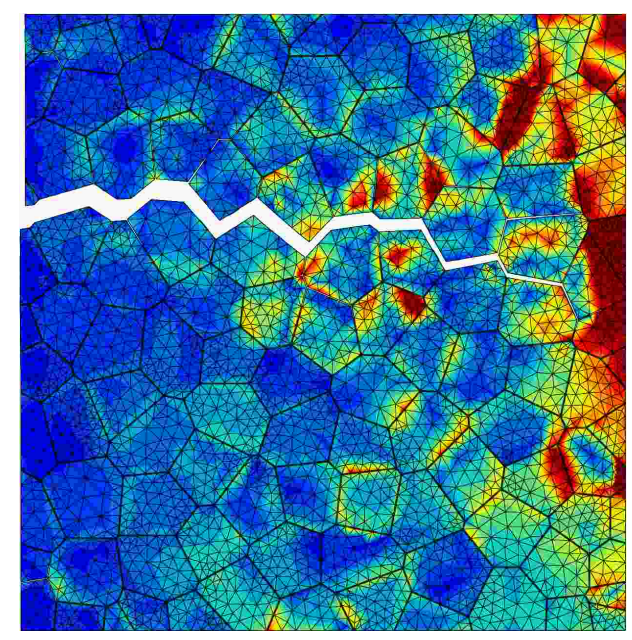

(e)

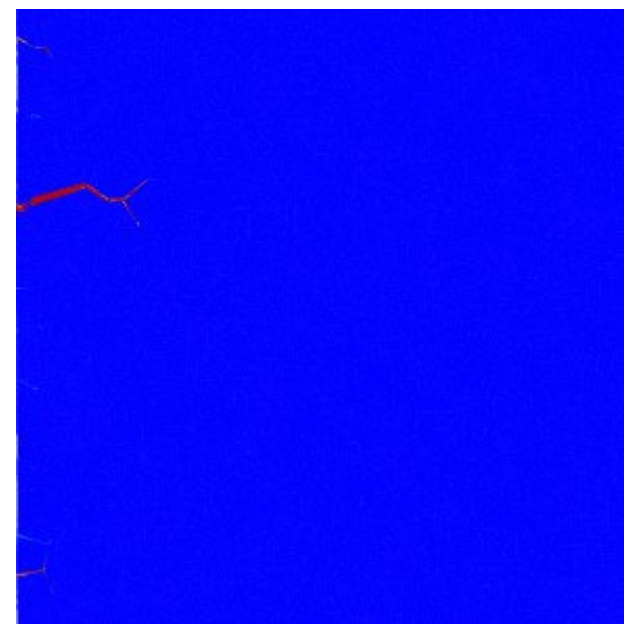

(b)

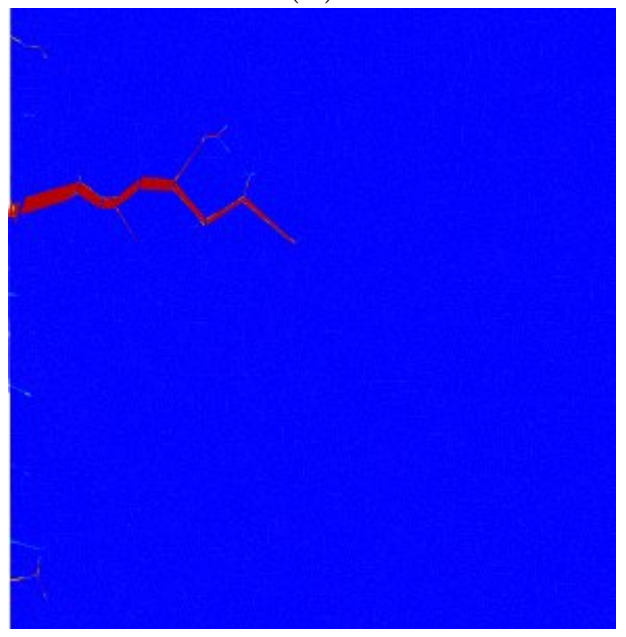

(d)

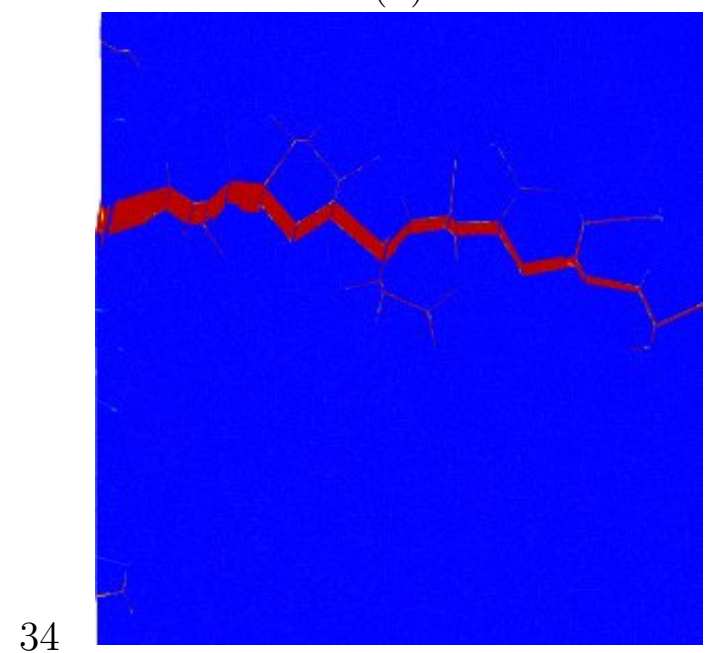

(f)
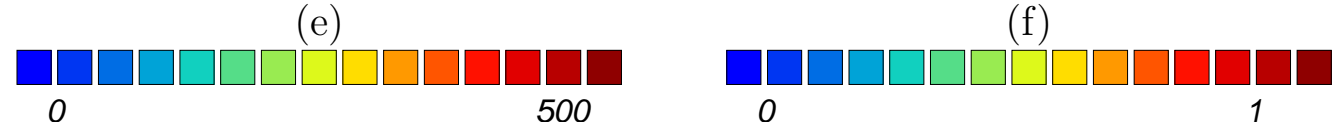

Figure 8: Contour maps during IG crack propagation for a 2D mesh (2DIG): (a) (c) (e) Von Mises stress; (b) (d) (f) damage fields evolution. (a) (b), imposed strain $\varepsilon=2 \%$; (c) (d) $\varepsilon=2.5 \%$; (e) (f) $\varepsilon=4 \%$ 


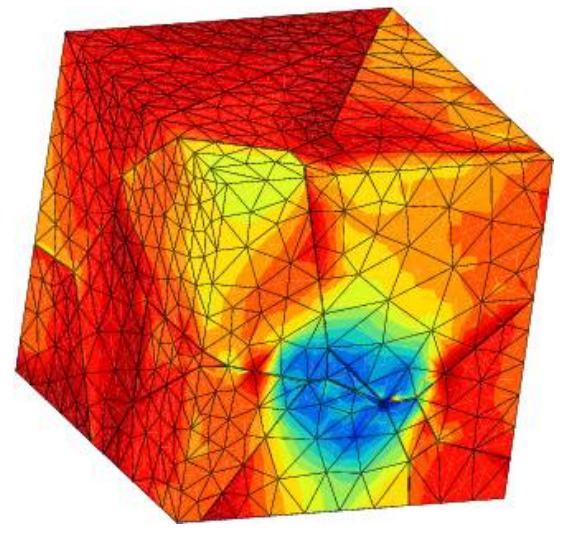

(a)

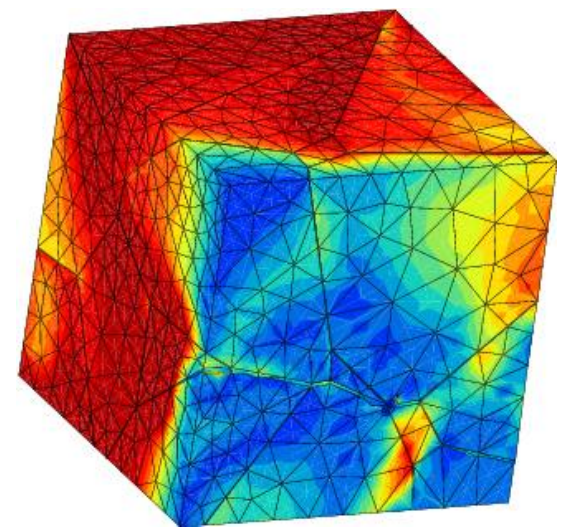

(c)

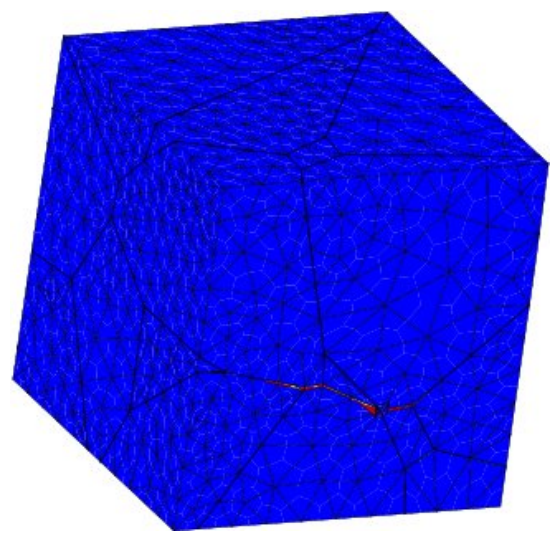

(b)

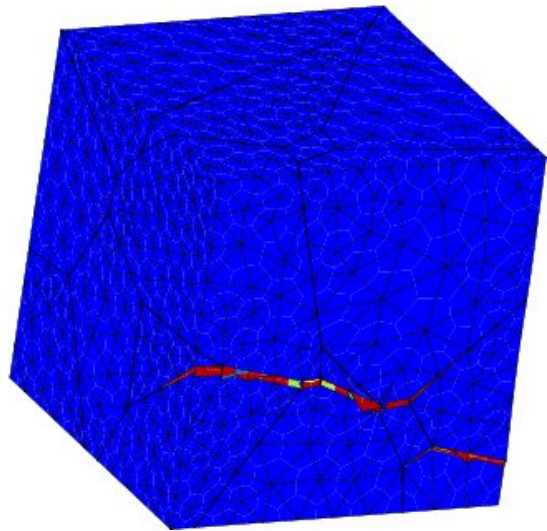

(d)
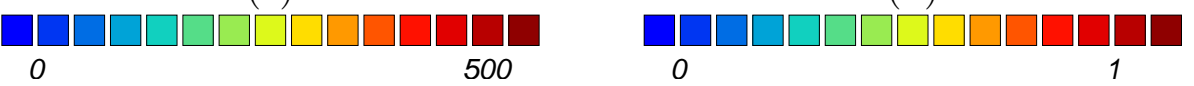

Figure 9: Contour maps during IG crack propagation for a 3D mesh (3DIG): (a) (c) Von Mises stress; (b) (d) damage fields evolution. (a) (b), $\varepsilon=1 \%$; (c) (d) $\varepsilon=2.5 \%$ 


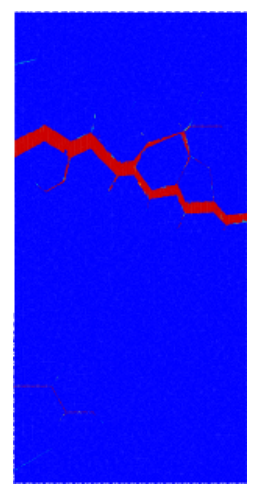

(a)

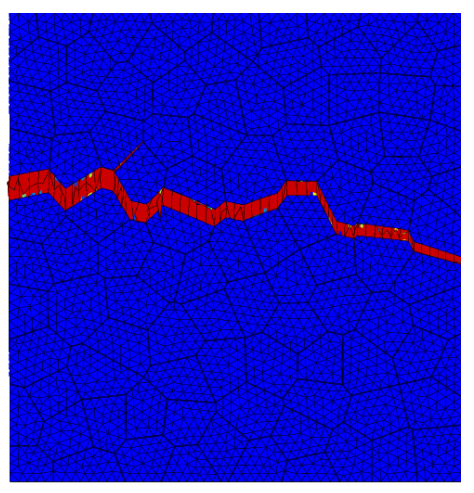

(b)

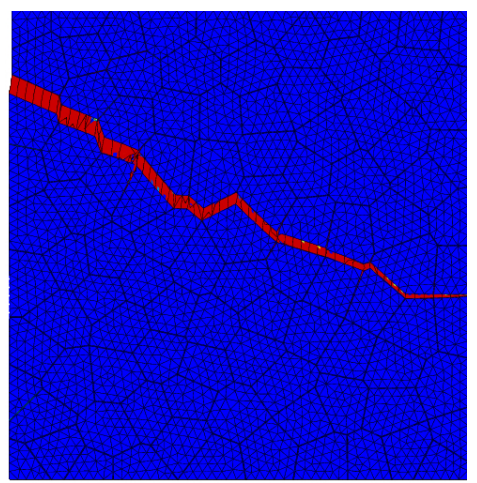

(c)

0

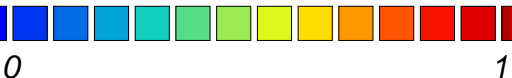

Figure 10: Damage fields for coupled tests for various random realizations: (a) 71gr2DIG; (b) 2DIG2; (c) 2DIG3

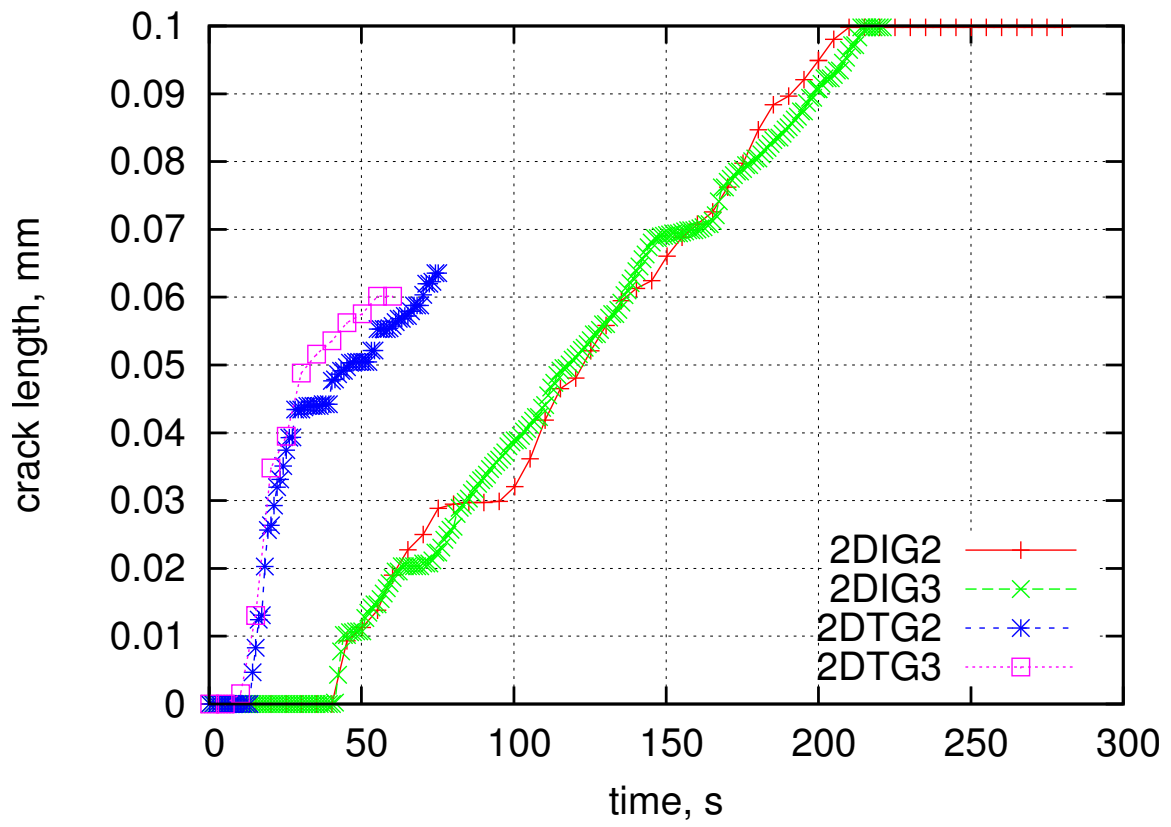

Figure 11: Crack propagation versus time for various mesh type, according to intergranular or transgranular mechanisms 


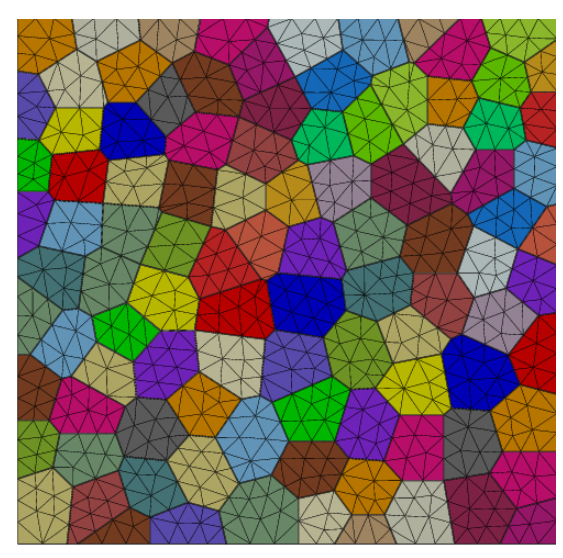

(a) 100gr2Ddens4

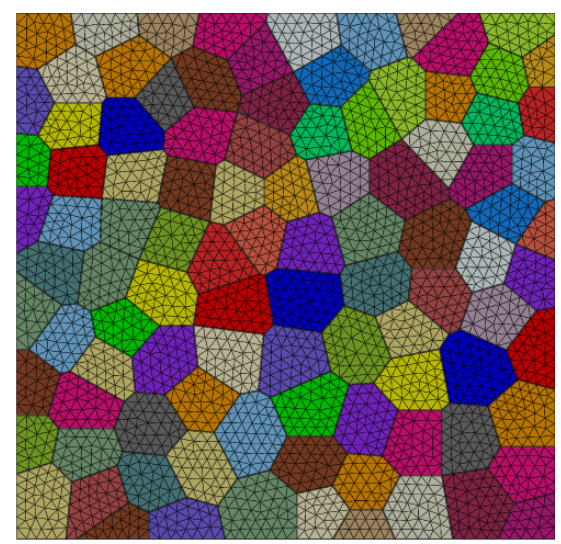

(c) 100gr2Ddens2

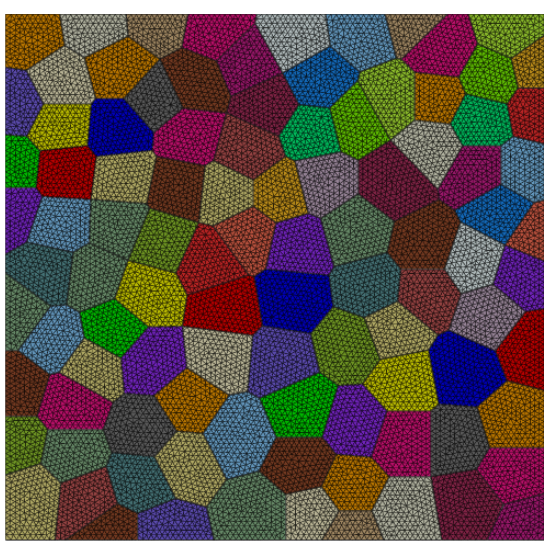

(e) 100gr2Ddens1

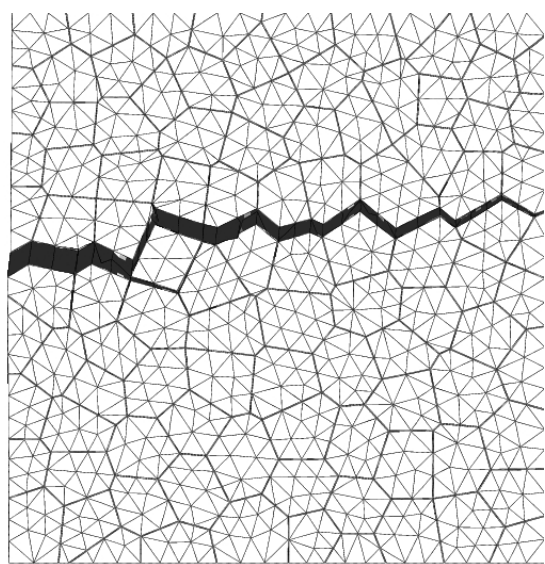

(b) 2DIGdens 4

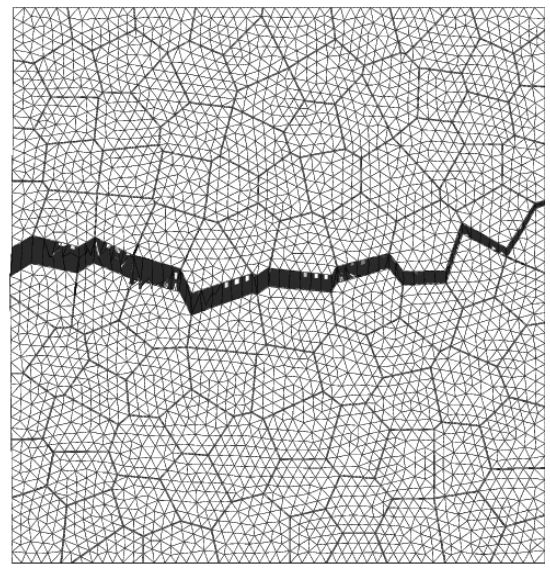

(d) 2DIGdens2

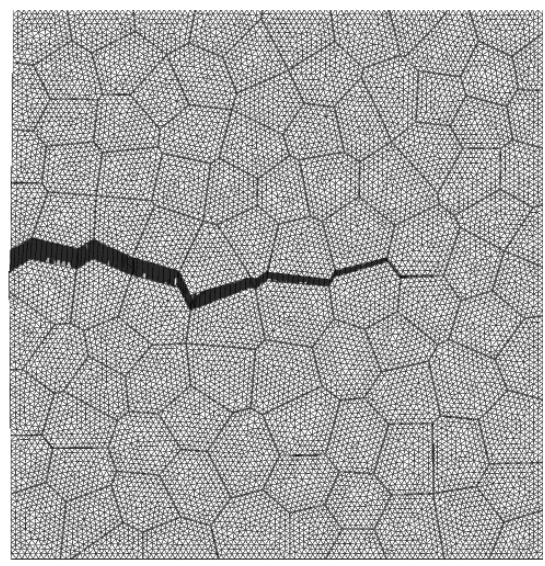

(f) 2DIGdens1

Figure 12: IG crack path for the aggregates of equivalent morphology, but various FE mesh density (13161 nodes, 37377 nodes, 125141 nodes) 


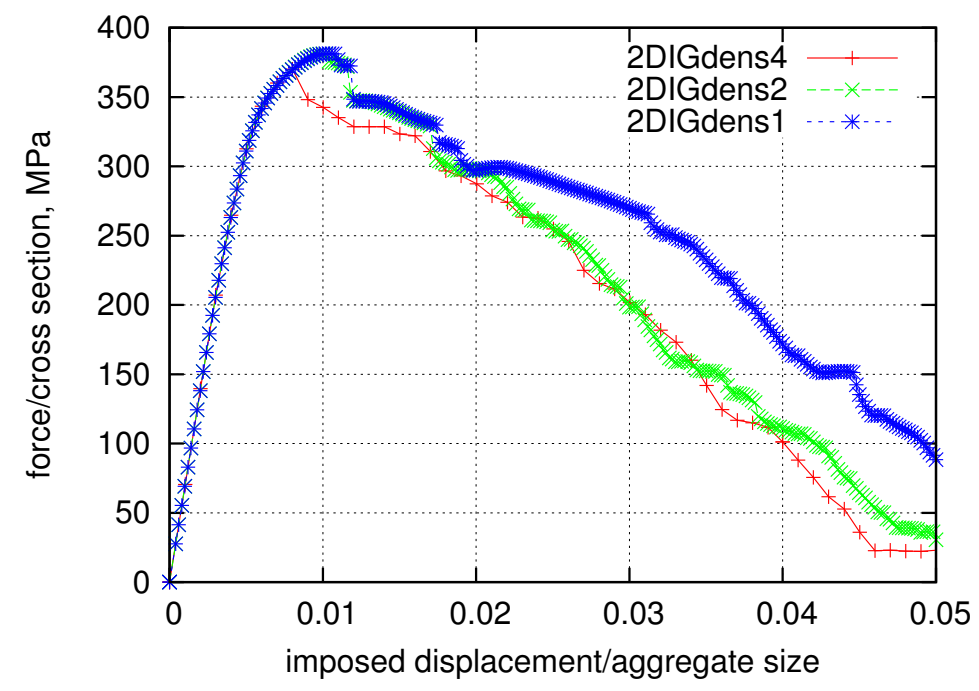

(a)

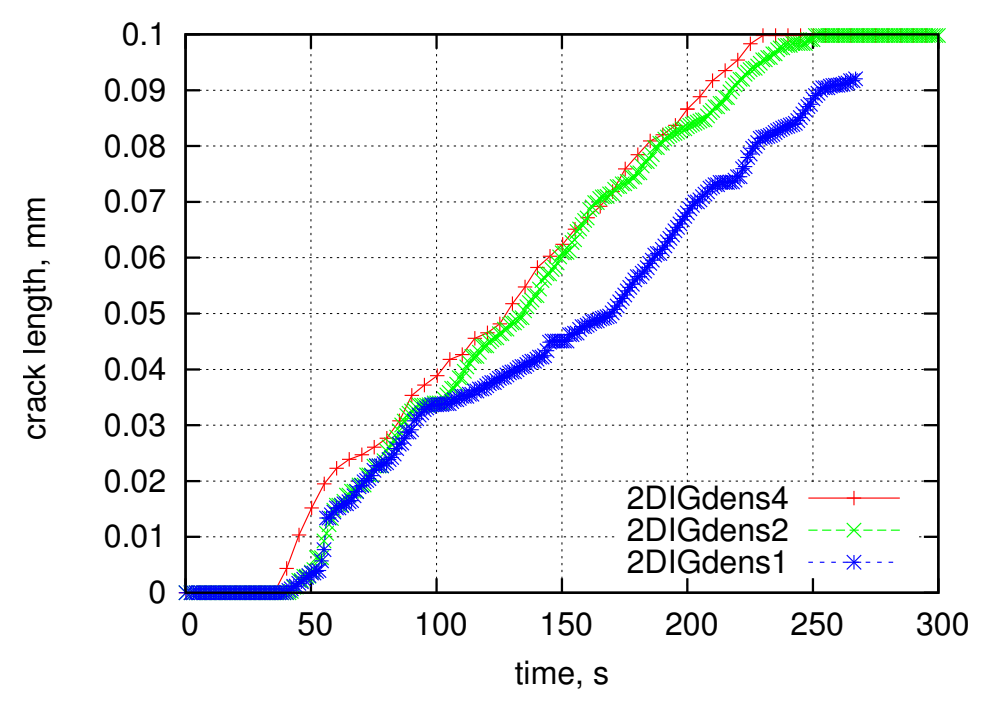

(b)

Figure 13: Illustration of the effect of mesh density (a) for global force displacement curve, (b) for crack projection length 

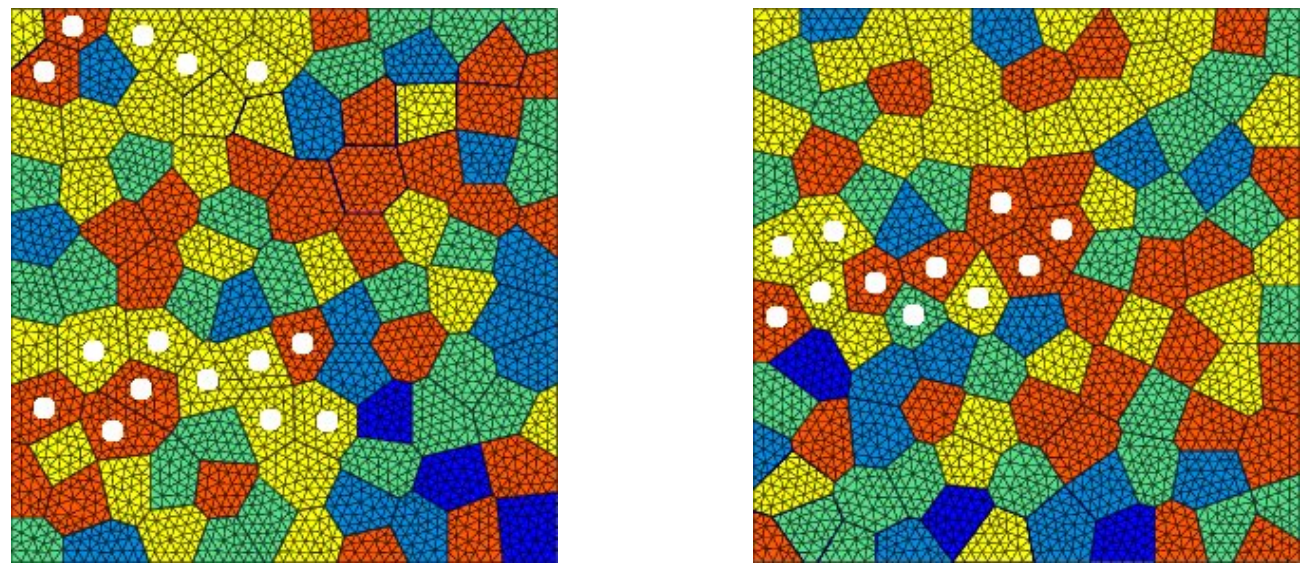

0

90

Figure 14: Maps of $\Phi$ Euler angle (rotation around X-axe) for 2DTG2 and 2DTG3 computations. Cleavage affected grains are marked with white points on $\Phi$-maps

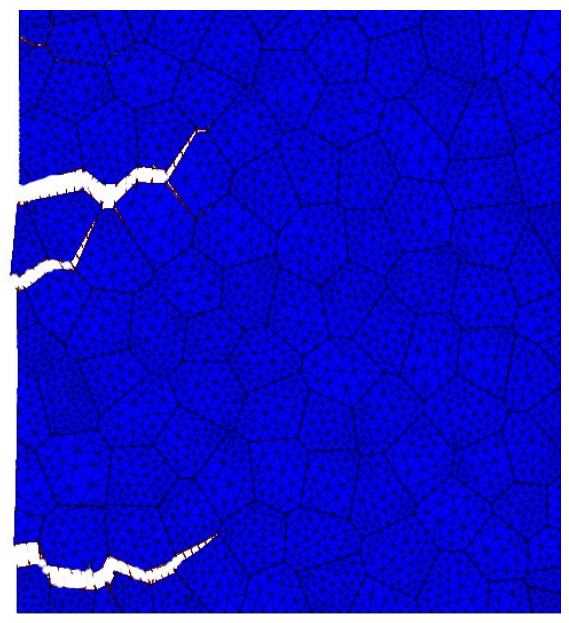

(a)

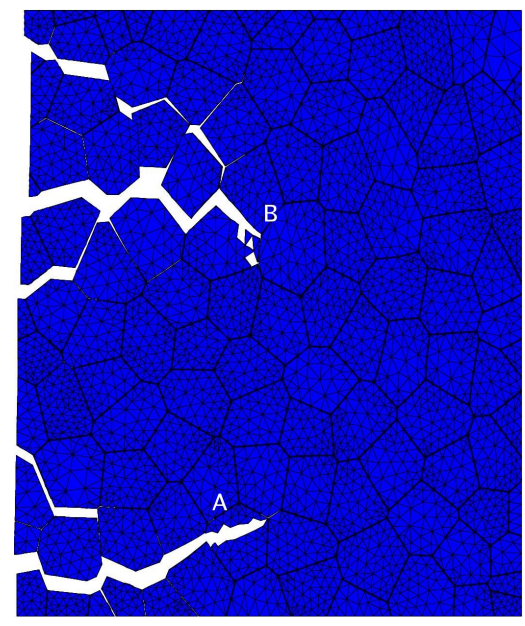

(b)

Figure 15: Crack paths in coupled problems performed with $\mathbf{D}_{s}$ type diffusion (a) for 2DIG problem (IG failure only), (b) for 2DIGTG problem 


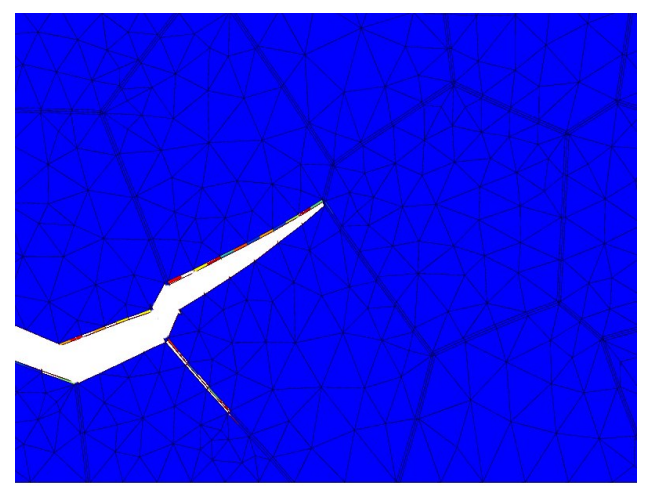

(a) before transition

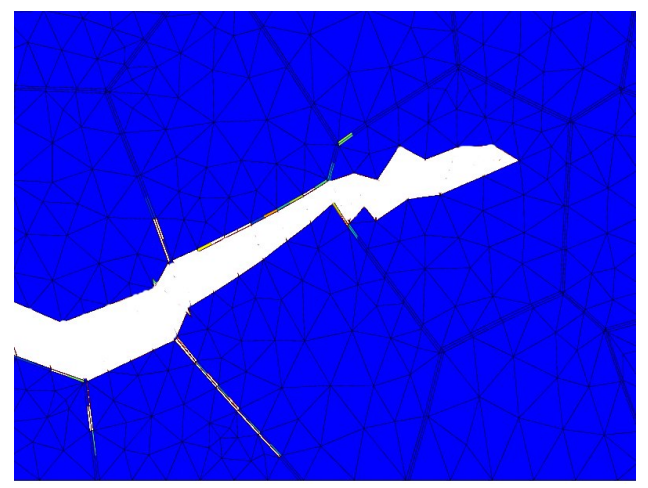

(c) 2DIGTG

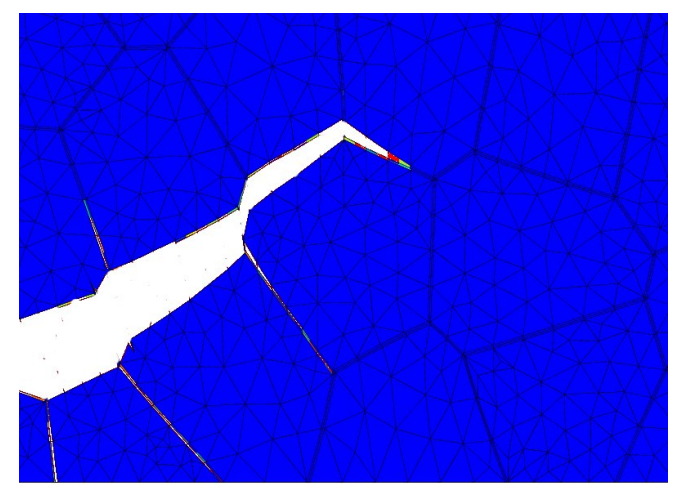

(b) 2DIG

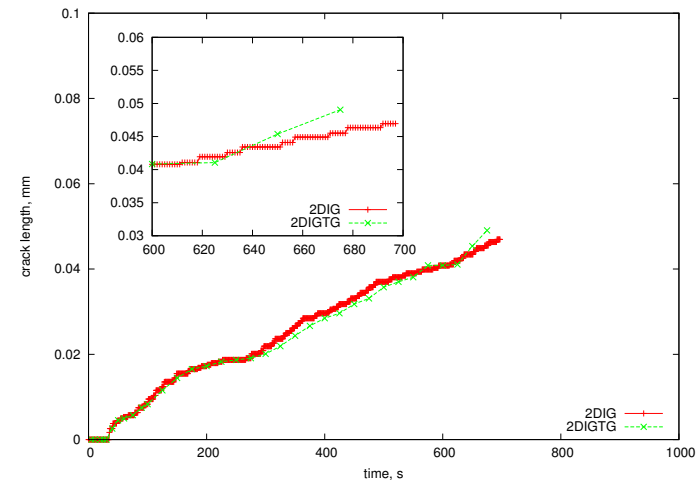

(d)

Figure 16: Illustration of the inter- transgranular transition on the 100gr2D_1 mesh: (a) position of the intergranular crack just before transition; (b) crack path for the IG model; (c) crack path for the IG+TG model; (d) crack length versus time 


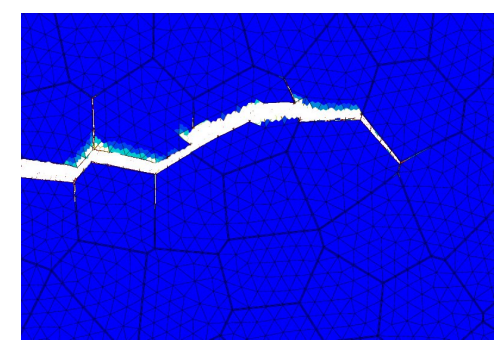

(a) 2DIGTG3

Figure 17: Observed crack path after inter-transgranular passage 


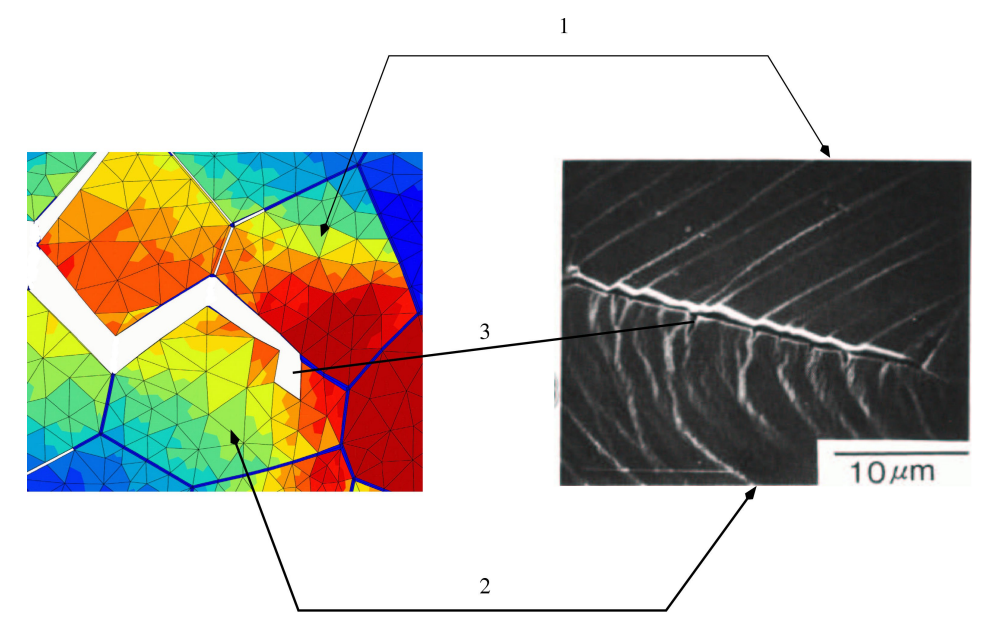

(a)
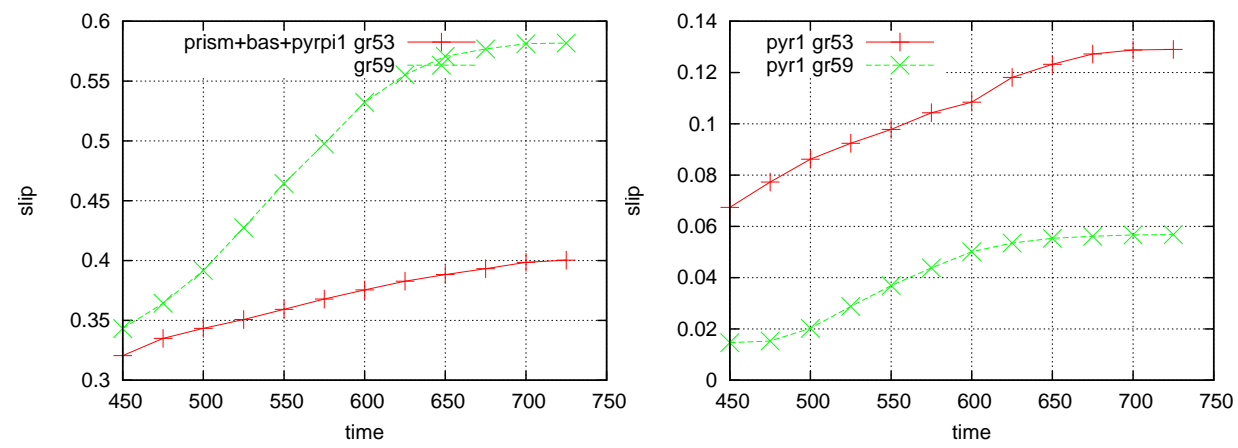

(b)

Figure 18: Mechanism of transgranular crack initiation (2DIGTG) reproducing the experimental observation shown in Fig.1c: 1 - grain (noted gr59) oriented for easy slip; 2 grain (gr53) with predominant pyramidal slip; 3 - transgranular crack initiation; (b) total slip and pyramidal slip activity for both grains versus time 